\title{
The Future of Macromarketing: Recommendations Based on a Content Analysis of the Past Twelve Years of the Journal of Macromarketing
}

\author{
Ahmet Ekici, '® Tugce Ozgen Genc,' and Hafize Celik'
}

\begin{abstract}
In their essays published in the Silver Anniversary Issue (SAI) of the Journal of Macromarketing (2006), George Fisk and Mark Peterson independently outlined the current state of the discipline and made a list of visionary recommendations that would help macromarketers adapt and respond to the changing markets, marketing, and societies. These recommendations ranged from repositioning the discipline around the ideas of societal development to leading the way across disciplines toward achieving a sustainable world. Based on a thorough content analysis of the articles published in the Journal of Macromarketing since the SAI, we aim to report the extent to which macromarketing scholarship has responded to the recommendations of Fisk and Peterson. Utilizing the findings, we make a list of new recommendations that can assist macromarketers in fulfilling their mission of 'saving the world'.
\end{abstract}

\section{Keywords}

societal development, sustainability, content analysis, macromarketing history

\section{Introduction}

The Silver Anniversary Issue (SAI) of the Journal of Macromarketing $(J M K)$ brought together many prominent macromarketers to collectively evaluate and examine the evolution of the discipline and to analyze its impact during the quarter century preceding the SAI. With its past and future orientation, the special issue reflected on the origins of the discipline and recommended new directions for the study of markets, marketing, and society. As Shultz (2006) stated in his Introduction to the Issue, the $[\mathrm{SAI}]$ aimed to "provide useful materials to researchers, theorists, teachers, and practitioners... inspire a new generation of scholars to champion macromarketing, and contribute to the next twenty five years of the Journal's growth and influence" (p. 127). The Ruby Anniversary is a fitting time to reflect on the SAI and the extent to which macromarketing scholarship has progressed accordingly.

Some of the contributing scholars of the SAI focused on the origins of the discipline and discussed the evolution of the discipline in general (e.g., Layton and Grossbart 2006; Mittelsteadt, Kilbourne, and Mittelsteadt 2006; Wilkie and Moore 2006). Others examined the evolution of a particular domain of macromarketing, such as ethics or history (e.g., Hunt and Vitell 2006; Jones and Shaw 2006; Laczniak and Murphy 2006). Most of the articles and essays to appear in the SAI were concerned with possible research endeavors and posited possible research foci for the particular macromarketing domain they discussed (Shultz 2006).

Two contributions published in the SAI, however, had a remarkably distinct agenda: the essays by George Fisk (2006) and Mark Peterson (2006) were written to communicate their visions for the future positioning of macromarketing amidst significant changes in the provisioning technology which was transforming markets and marketing. More specifically, Fisk (2006) and Peterson (2006) (F\&P) devoted their essays to making specific recommendations for macromarketers (and for the future of macromarketing) so that the discipline could fulfill its mission in the coming decades. The purpose of this article is to conduct a thorough content analysis of the articles published in the $J M K$ over the last twelve years, report whether and to what extent the visions and recommendations of F\&P have taken place within the discipline, and make further suggestions toward the fulfillment of these visions.

In "Envisioning a Future for Macromarketing," Fisk (2006) outlines his vision as well as new directions for the discipline.

\footnotetext{
'Faculty of Business Administration, Bilkent University, Ankara, Turkey
}

\section{Corresponding Author:}

Ahmet Ekici, Faculty of Business Administration, Bilkent University, Ankara 06800, Turkey.

Email: ekici@bilkent.edu.tr 
His essay provides recommendations that would extend macromarketing knowledge beyond its present limits. He encourages macromarketing scholars to be more inclusive and expansive toward other disciplines, and to engage in more analytical reasoning and empirical research that is valued by other academic domains and practitioners. More specifically, he recommends macromarketing researchers have an internal focus on developing metrics and analytic skills in order to examine macromarketing issues, and at the same time, an external focus on developing collaborations with researchers in other disciplines (p. 217).

In "Focusing the Future of Macromarketing," Peterson (2006) argues that macromarketing research has the potential to become a transdisciplinary scholarship if it redefines itself and focuses on societal development. He argues this new focus (i.e., societal development) would be the "unifying big idea" that would combine multiple disciplines and fuel synergy and development to the domain (p. 247). Similarly to Fisk's arguments (2006), Peterson (2006) sees transdisciplinary work as the backbone of redefined macromarketing (which focuses on societal development). He argues engaging in transdisciplinary work can help us better understand the challenges and dynamics of globalization, and consumers/markets in different parts of the world.

To summarize, in their SAI essays, F\&P collectively highlight the possible future routes for the macromarketing domain. They, independently, provide specific recommendations for macromarketing researchers. As noted, our objective is to conduct a thorough content analysis to examine the extent to which macromarketing scholarship, as represented within the $J M K$, has responded to the calls made by F\&P. We hope this will reinvigorate the visions of $F \& P$, affirm the tremendous progress that has been made by macromarketers, generate new ideas for the study of macromarketing, and introduce a new generation of scholars to the vision for our discipline.

In the following sections, we start by providing information about our study, which includes two-stage content analysis. Then, we explain the recommendations made by F\&P based on the five main categories identified in the first stage of the content analysis. Each category is justified with the arguments made by the authors in their 2006 articles. We also provide the domains (sub-categories) of each category and a brief explanation of the coding protocol. Finally, we provide the results of the content analysis along with their explanations and interpretations.

\section{The Study}

We conducted a two-stage content analysis; that is, we (1) defined and classified the recommendations of F\&P, and (2) assessed the extent to which the works that have appeared in the $J M K$ over the last twelve years have fulfilled these recommendations. For the first stage, all three researchers independently identified (i.e., listed) the recommendations made by F\&P. The researchers then met multiple times to iteratively compare and contrast their lists, resolve any inconsistencies, and finally, identify a code sheet of the themes (categories) and their domains (subcategories) for the second stage of the content analysis (Table 1). These themes and their domains will be explained in detail in the next section.

The second stage involved the content analysis of all the articles that appeared in the $J M K$ between 2008 and 2019 (inclusively). In other words, the unit of analysis in this study was the articles that appeared in the $J M K$ during this twelveyear period. All 291 original/research articles were contentanalyzed based on the categories and subcategories identified during the first stage. Book reviews, commentaries, communication papers, and editorials were not included in the content analysis. Coding was performed by two of the researchers, who were trained by the principle researcher through a semesterlong seminar on macromarketing as well as numerous rounds of practice sessions on coding protocols. The principle researcher has been involved in the Macromarketing Society for the last 20 years as an author, reviewer, conference track chair, and member of the editorial team. During the training sessions, the authors determined the criteria they would use for coding. In addition, the authors conducted test coding on randomly selected articles to address potential problems in coding as well as to improve the intercoder agreement. The principle researcher participated in the test coding stage to cross-check the coding done by the other two coders. Table 2 provides the checklist the researchers used to decide whether or not the content of each article fulfilled the predetermined inclusion criteria. After the training, the coders conducted content analyses independently based on the predetermined coding protocol. A nominal (dichotomous) scale was used to determine the presence of each of the themes and their domains. A value of 1 was assigned for the presence of a category, and a value of 0 was assigned for its absence. The coders continued to meet to reach an agreement on the disputed cases. When there were disagreements, the principle researcher joined the conversation. All three researchers jointly discussed and resolved any inconsistencies and disputes over the coding of the articles.

Intercoder reliability is a prerequisite for the validity of a content analysis research. Without reliability assessment, content analysis measures are deemed "useless" (Neuendorf 2002, p.141). Accordingly, the lack of a reliability assessment is a "fatal flaw" in a content analysis research; without it, readers cannot evaluate the validity of the data (Riffe, Lacy, and Fico 2014, p. 1135). Intercoder reliability demonstrates the extent to which two or more coders categorize content units into the same categories by using the same coding protocol (Lovejoy et al. 2014). Intercoder reliability is calculated in the form of percent agreement or reliability coefficients. While percent agreement is the simple calculation of percentage of observed agreement, reliability coefficients compute the possibility of chance in agreements. Thus, reliability coefficients such as Cohen's Kappa (Cohen 1960), Scott's pi (Scott 1955), and Krippendorff's alpha (Krippendorff 1980) are referred to as conservative indices, compared to percent agreement, which is known to be a more liberal indicator of intercoder reliability. While $80 \%$ is the minimum acceptable level for percent 
Table I. List of Categories and Subcategories.

\begin{tabular}{|c|c|}
\hline Categories & Subcategories \\
\hline \multirow{4}{*}{ Unifying Focus of Societal Development } & Well-Being / Quality of Life (QOL) \\
\hline & Poverty \\
\hline & Food and Agriculture \\
\hline & Equality / Fairness \\
\hline \multirow[t]{3}{*}{ Transdisciplinary Approach } & Multidisciplinary communication from other disciplines \\
\hline & Multidisciplinary communication to other disciplines \\
\hline & Collaboration with researchers from other disciplines \\
\hline \multirow[t]{3}{*}{ Methods \& Metrics } & Marketing Systems Analysis / Network Analysis \\
\hline & Meta-analysis of existing studies \\
\hline & Comparative analysis of different nations \\
\hline \multirow[t]{3}{*}{ Guidance Role } & Normative language with government / policy makers \\
\hline & Normative language with business \\
\hline & Creation of awareness about provisioning role of marketing for societal development \\
\hline \multirow[t]{2}{*}{ Horizontal Thinking } & Developmental approach instead of critical approach \\
\hline & Thinking broadly across subject matters \\
\hline
\end{tabular}

agreement (Neuendorf 2002), this value drops to .75 for Scott's pi and Krippendorff's alpha (Wimmer and Dominick 2003). A preferred approach is to report at least two of the reliability coefficients (Neuendorf 2002) together with the percent agreement for each category in the coded sheet. On the other hand, Lovejoy et al. (2016) point out a controversy between these two types of intercoder reliability measures: reliability coefficients may produce very low values, even though the percent agreement value is high (Feng 2015; Gwet 2008; Zhao, Liu, and Deng 2012), if the data have insufficient variation (Krippendorff 2013). Studies dealing with populations with skewed distributions of categories may prefer to report only percent agreement. Thus, in this study, reliability coefficients Scott's pi (Scott 1955) and Krippendorff's alpha (Krippendorff 1980) were calculated and reported for only the main categories due to insufficient variation in their domains. Percent agreement was calculated and reported for both categories and their domains.

For the purpose of the intercoder reliability check, each coder was assigned 16 articles (32 articles in total, $11 \%$ of the population) previously coded by the other coder. We sought not to have a sample size less than $10 \%$ of the population (Lombard, Snyder-Duch, and Bracken 2005). Combinations of stratified random sampling and purposive sampling were used to ensure a representative sample. First, articles were randomly selected from each year, starting from a random issue and carrying on with respective ones. Second, some articles were selected purposively to ensure the inclusion of rare types (such as meta-analysis and experimental studies) that were not represented in the first selection. As seen in Table 3, the intercoder reliabilities for all categories are higher than the threshold values of each indicator.

\section{Categories and Their Domains}

\section{Societal Development}

Peterson (2006) recognizes in his SAI article the accomplishments of macromarketing scholars who contributed to the development of the field based on six subareas: (1) competition and markets, (2) marketing and development, (3) marketing ethics and distributive justice, (4) global policy and environment, (5) quality of life, and (6) marketing history. At the same time, he claims that a unifying focus (rather than eclectic approaches) to study the macromarketing phenomena would provide greater recognition to macromarketing scholarship and enhance its image in the minds of scholars across disciplines. According to him, this focus should be societal development because societal development-implicitly or explicitly-has always been in the minds of macromarketers. As societies (including commerce, consumers, etc.) develop via the impact of globalization, there is a clear opportunity for macromarketers to position the discipline toward this direction. After all, "saving the world" has always been the principle goal of macromarketers (p. 245). If they miss this opportunity, it is inevitable that many macromarketers will have to move to other interdisciplinary areas. In other words, to save the world and macromarketing, it is crucial to adopt a unifying focus in societal development. 
Table 2. Criteria Used for Exclusion.

\begin{tabular}{|c|c|c|}
\hline Goals & Recommendations & Exclusion Reasons \\
\hline \multirow{2}{*}{$\begin{array}{l}\text { Unifying Focus of } \\
\text { Societal } \\
\text { Development }\end{array}$} & \multirow{2}{*}{ Subthemes } & Historical analysis without any societal implications \\
\hline & & $\begin{array}{l}\text { Studies that interpret main results with a limited perspective and for the benefit of } \\
\text { commercial parties }\end{array}$ \\
\hline \multirow{4}{*}{$\begin{array}{l}\text { Transdisciplinary } \\
\text { Approach }\end{array}$} & \multirow{2}{*}{$\begin{array}{l}\text { MD Communication } \\
\text { (from others) } \\
\text { MD Communication } \\
\text { (to others) }\end{array}$} & Articles that don't connect the study to a variety of other disciplines \\
\hline & & $\begin{array}{l}\text { Articles that don't provide suggestions to other disciplines such as further research } \\
\text { (Based on direct language, not interpretation) }\end{array}$ \\
\hline & \multirow[t]{2}{*}{ Collaboration } & $\begin{array}{l}\text { Studies that are conducted by single author (regardless of whether or not the discipline } \\
\text { he or she belongs to is marketing) }\end{array}$ \\
\hline & & $\begin{array}{l}\text { Studies that are conducted by multiple authors belonging to same discipline (no } \\
\text { diversity) }\end{array}$ \\
\hline \multirow{2}{*}{ Guidance Role } & $\begin{array}{l}\text { Normative dialogue with } \\
\text { PPM and/ or business }\end{array}$ & $\begin{array}{l}\text { Studies that provide general implications of main results without suggesting any course } \\
\text { of action and/ or addressing any accountable party }\end{array}$ \\
\hline & Role of Marketing & $\begin{array}{l}\text { Studies that lack dialogue for communication macromarketing knowledge as a } \\
\text { contributing to the alleviation efforts field for societal wicked issues }\end{array}$ \\
\hline \multirow[t]{4}{*}{ Methods \& Metrics } & $\begin{array}{l}\text { Role of Reward in behavior } \\
\text { change }\end{array}$ & Studies that lack focus on reward while examining behavior change \\
\hline & Experimental Studies & Non-experimental studies \\
\hline & Meta-analysis & Articles that carry no meta- \\
\hline & Comparative Analysis & $\begin{array}{l}\text { Studies that constitute not providing detailed comparisons of countries in the literature } \\
\text { Studies conducted in a single context or in multiple contexts but not with a purpose of } \\
\text { comparison (but to enlarge the observation point or sample size) }\end{array}$ \\
\hline \multirow[t]{5}{*}{ Horizontal Thinking } & \multirow[t]{2}{*}{ Developmental Approach } & $\begin{array}{l}\text { Studies that just describe a relationship but do not indicate practical implications for an } \\
\text { improvement }\end{array}$ \\
\hline & & Critical studies that do not suggest any possible solution \\
\hline & \multirow[t]{3}{*}{ Thinking Broadly } & Studies that integrate limited stakeholders into analysis \\
\hline & & $\begin{array}{l}\text { Studies that discuss only positive side of a controversial issue even though negative } \\
\text { impacts are obvious }\end{array}$ \\
\hline & & $\begin{array}{l}\text { Studies that are conducted with a bottom-up approach with the assumption that micro } \\
\text { level changes will have macro level impacts }\end{array}$ \\
\hline
\end{tabular}

Fisk (2006) points out that a shift in the focus of macromarketing has already started, even without the influence of macromarketers, due to current developments in globalization, consumerism, and innovation. Therefore, it is time for macromarketers to lead/direct this shift toward a globally sustainable society. While Peterson (2006) builds his argument on societal development in general, Fisk (2006) specifically points out the sustainable society, as the issue of sustainability is decisively becoming the priority of all nations. He urges the importance of moving the focus of marketing studies away from the maximization of customer satisfaction and entrepreneurial profit and toward sustainable consumption/business by demonstrating the long-range consequences of trade globalization. Alongside the study of social benefits, one should also consider the social costs of trade globalizations (such as economic disruptions, poverty, environmental deteriorations, social disorder, and reduced longevity). Hence, Fisk (2006) put the sustainability of global consumption ahead of all other themes of societal development in the new vision of macromarketing. In addition, he believes this new vision is highly compatible 
Table 3. List of Societal Development Subcategories.

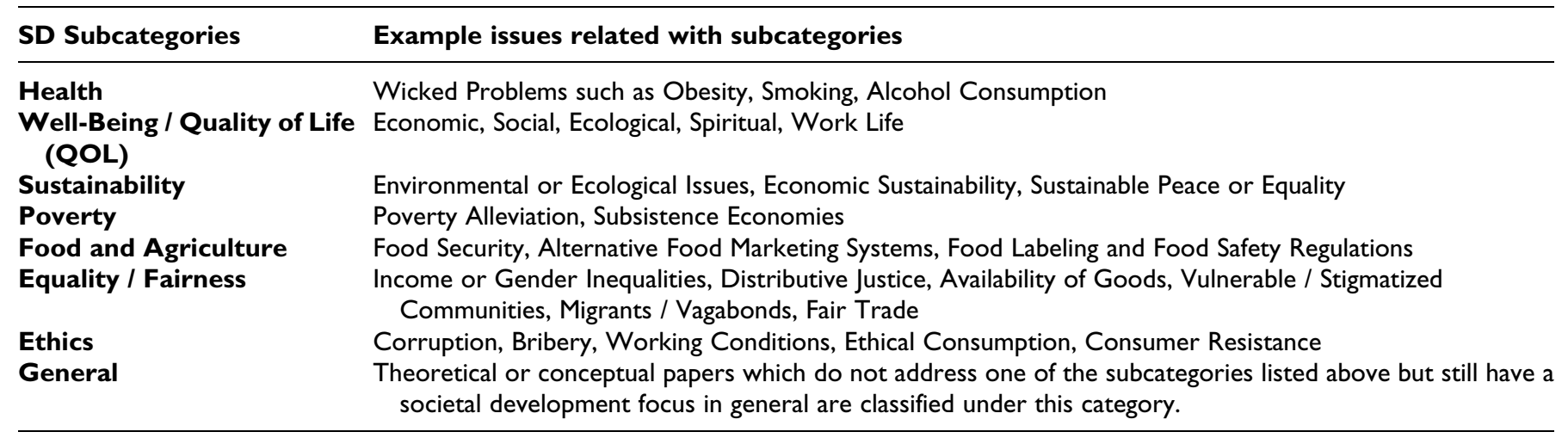

with historical accounts of marketing, which posit marketing is an aid to societal development.

In this study, considering the accounts of F\&P, we determine societal development as an umbrella theme and sustainability as one of its subcategories. However, it is necessary to note the challenges of identifying a specific definition and/or description for the term societal development, from the accounts of these two scholars. While F\&P offer some examples that constitute an initial framework of the societal development focus, the authors did not provide a focus to their definition, structure, and scope of societal development from a macromarketing perspective. The extant literature, however, provides certain directions that can help identify the various components of the term. For example, one conceptualization states that "(s)ocial development is about improving the wellbeing of every individual in society so they can reach their full potential. The success of society is linked to the well-being of each and every citizen. To sum up, the (concept) includes eliminating poverty, sustaining economic growth, and improving health, environment, well-being, and equality etc." (GNB 2020). Similarly, the conceptualization offered by the World Bank points out issues such as "... social inclusion of the poor and vulnerable by empowering people, building cohesive and resilient societies, and making institutions accessible and accountable to citizens" (The World Bank 2020). Based on the synthesis of the ideas and arguments of F\&P and the conceptualizations of societal development, we propose seven subcategories under the overarching category of Societal Development (SD) (Table 4).

When coding for this category, we paid attention to solicit articles that particularly address at least one of the subcategories listed in Table 4. Regardless of the unit or level of analysis (micro, meso, or macro), we sought direct connection between the main arguments/results of the papers and their societal development implications. For instance, one of the articles we reviewed explores the possible ways to increase consumer acceptance of companies' green messages. From the unit-of-analysis perspective, this study can be classified as micro. However, the paper could also be considered as adopting a unifying focus of societal development, as it extensively discusses how micro-level changes are necessary to create societal changes for a better future. In addition, we allowed one paper to be classified under several categories. For example, if a study analyzes an alternative food marketing system to show how different stakeholders' QOL is improved, as well as how environmental degradation is reduced, then this study is classified under well-being/QOL, sustainability, and food and agriculture.

\section{Transdisciplinary Approach}

While envisioning the future of macromarketing, Fisk (2006) urges macromarketers to have an external focus (i.e., to develop collaborations with researchers from other disciplines). Multidisciplinary communication is vital to broaden the macromarketing knowledge beyond its current boundaries. One aspect of multidisciplinary communication is utilizing knowledge generated in other disciplines. The other aspect of external focus deals with the aggressive communication of macromarketing knowledge to others so that macromarketers can influence the progress of sustainability research. Without an external focus it would be difficult to disseminate the exterminating effects of provisioning technology on poverty, disease, and environmental degradation to other scientific communities/disciplines (Fisk 2006).

Peterson (2006) urges macromarketers to make a transdisciplinary effort to engage with all types of scientists. Being transdisciplinary means working with teams of researchers from other fields (Fisk 2005). For F\&P, a transdisciplinary approach is necessary to understand development. In this way, researchers would have a better chance of seeing the whole picture, and thus, proposing effective solutions. In addition, according to Peterson (2006), of the six subgroups of Marketing and Society (public policy and marketing, macromarketing, consumer economics, social marketing, marketing ethics, and international consumer policy), macromarketing possesses the greatest capacity to take over the role of initiator in multidisciplinary research; this would likely create a competitive edge for the discipline (p. 245).

As such, we consider whether a study adopts a Transdisciplinary Approach (TA) based on the following three subcategories (derived from the visions of F\&P): 
Table 4. Intercoder Reliability Based on 32 Randomly-selected Articles (I I\% of the Population).

\begin{tabular}{lccc}
\hline & & Intercoder Reliability \\
\cline { 2 - 5 } Categories \& Subcategories & $\begin{array}{c}\text { Percent Agreement (\%) } \\
\text { (Threshold: 80) }\end{array}$ & $\begin{array}{c}\text { Scott's pi } \\
\text { (Threshold: .75) }\end{array}$ & $\begin{array}{c}\text { Krippendorffs alpha } \\
\text { (Threshold: .75) }\end{array}$ \\
\hline Unifying Focus of Societal Development & 100 & $\mathrm{I}$ & $\mathrm{I}$ \\
Transdisciplinary Approach & 100 & $\mathrm{I}$ & $\mathrm{I}$ \\
Methods and Metrics & 100 & .87 & .872 \\
Guidance Role & 93.8 & .763 & .767 \\
Horizontal Thinking & 93.8 & & $\mathrm{I}$ \\
\hline
\end{tabular}

i. Multidisciplinary communication by utilizing knowledge from other disciplines (MCU): a study utilizing knowledge produced by other disciplines is classified under this category.

ii. Multidisciplinary communication by providing knowledge to other disciplines (MCP): a study which addresses other disciplines for the use of knowledge it produces. Here, the explicit addressing is the main qualification criterion to avoid any misinterpretation and inconsistency between cases.

iii. Collaborations with researchers from other disciplines (CRD): for this category, we sought articles that involve multiple researchers (at least two of which are from different fields). Diversity is the main qualification, rather than that of having the research team involve scholars who are not market(ing) researchers. For example, even if a paper is written by scholars outside of the marketing discipline, if all authors belong to the same field (e.g., all authors are from the accounting discipline) then the article is excluded.

\section{Methods and Metrics}

Between the two authors, it is Fisk (2006) who provides a specific list of methodology-related recommendations. He points out the absence of marketing systems analysis. According to him, conducting marketing systems analysis could be an effective way to capture the attention of the researchers working on productivity improvements in other fields. Furthermore, marketing systems analysis and network analysis could be influential to illuminate the provisioning role of marketing in societies to those who conceive that marketing is a cost of capitalism (Fisk 2006).

Fisk (2006) also argues that before designing new studies, macromarketers should conduct and publish meta-analyses of existing studies. Meta-analyses would help identify gaps in knowledge and provide future research directions. Metaanalyses would also provide richer insights on macromarketing domains, and therefore, help the discipline reach-out to wider audiences (including managers, administrators, policymakers, and scientists from different disciplines). In other words, metaanalyses would provide opportunities to create a "shared language" (p. 217) with other disciplines and stakeholders, and as a result, facilitate future advancement in the macromarketing field.

Moreover, Fisk (2006) points out the importance of comparative analyses of different nations (as he believes they are highly underrepresented in the research of macromarketers). Examining behaviors and/or attitudes among population groups could shed light on the decisions of managers and/or public policymakers. Peterson (2006) highlights the importance of macromarketing scholars who study societal development in developed countries. The main reason behind his argument is that developed countries have already made progress, for instance, by adopting sustainability development programs; therefore, their experiences would provide valuable insights to the macromarketers who are studying similar issues in other (developing) country contexts.

Even though most research focuses on penalties as the most effective way to achieve a sustainable society, Fisk (2006) highlights the crucial role of rewards in changing behaviors toward a sustainable direction. Therefore, he calls for studies that test the effects of rewards rather than penalties. He also makes specific calls for experimental studies that would help understand the boundaries of consumption addiction because such behavior is a significant threat to the sustainability of societies.

Finally, while envisioning the future of macromarketing, in addition to an 'external focus', Fisk (2006) points out the importance of an 'internal focus' (i.e., developing metrics and analytic skills with which to explore macromarketing phenomena). The development and/or adoption of shared analytic measures and performance standards are critical for the development of globally sustainable consumption. Such an approach is also the key to impacting other disciplines and public and private decision makers. Fisk (2006) states that measures related to the supply and demand aspects of markets are particularly needed, as markets are encountering innovative changes due to resource scarcities. Even though the recommendation is labeled as internal focus, it is still necessary to have a transdisciplinary approach. The development of a shared language will be easier and more effective when macromarketers become familiar with cognate disciplines, such as social psychology or economics (Fisk 2006).

In addition to Fisk's suggestions, Peterson (2006) states an expectation from marketing historians to go beyond being 
descriptive and provide implications for the societal development of current conditions as a result of their insightful analysis of the past. Based on the above-mentioned recommendations, we identify a total of eight subcategories under the Methods and Metrics (MM) category:

i. Marketing systems analysis / network analysis.

ii. Meta-analysis of existing studies.

iii. Comparative analysis of different nations: studies examining at least two divergent contexts are classified under this category.

iv. Developed versus developing country contexts.

v. Studies that deal with the reward effect on behavior change.

vi. Experimental studies to delineate the boundaries of consumption practices: even though Fisk (2006) specifies the study of addiction practices, we searched for experimental studies in all domains.

vii. Development and adoption of shared analytic measures and performance standards.

viii. Insightful analysis of the past: descriptive studies are excluded even though they are historical.

\section{Guidance Role}

Fisk's (2006) recommendations in this domain predominantly deal with providing guidance for businesses and policymakers. He believes that, to influence sustainability research progress, macromarketing scholars should target policy-making communities. Practicality of the metrics and performance standards developed by macromarketers (such as consumer confidence metrics) would provide guiding choices for business and public policy, and enhance their decision-making processes. He considers policy-centered empirical macromarketing studies an instrument to reach wider audiences. He consistently accentuates that the core purpose of producing knowledge is to guide governments/policymakers and businesses in building a more sustainable society.

In other words, Fisk (2006) maintains a standpoint that casts macromarketing in a role of providing guidance for governments/policymakers and businesses in their decisions concerning sustainability. For example, if sustainable consumption is the desired target to overcome shortages of energy resources, then macromarketing analysis can investigate issues such as market and consumer acceptance of renewable energy and changing consumption patterns; consequently, it will help accelerate the adoption of sustainable energy consumption practices. However, the potential influence of marketing scholarship on sustainability is not yet recognized by public and private institutions; therefore, another important aspect of the guidance role of macromarketing should be to create awareness about the crucial provisioning role of marketing in sustainable development.

Peterson (2006) agrees with Fisk's account that macromarketing should attend to normative questions as well as the descriptive, explanatory, and predictive inquiries (Fisk 1981). He further states that those providing implications for societal development should not be criticized for becoming advocates of something, and that addressing normative questions does not make one less scholarly.

Based on the above arguments, we identify three subcategories under the category of Guidance Role (GR):

i. Normative dialogue with government / policymakers (NDPP).

ii. Normative dialogue with business (NDB).

iii. Creation of awareness about the provisioning role of marketing for societal development (CR).

Through the content analysis, we identified explicit normative cases, which address either business and/or policymakers. Therefore, if a study provides implications without specifying a target audience, it was excluded. Moreover, while evaluating whether an article conformed to the 'creation of awareness' (the third subcategory), we sought for obvious discussions around the positive and negative impact assessment of marketing on societal issues.

\section{Horizontal Thinking}

Peterson (2006) suggests that if macromarketers can be successful in positioning the discipline while it becomes a transdiscipline, this effort will help to "better envision pathways to the future for societies". As a means to this end, he offers "horizontal thinking" instead of "vertical thinking" (p.247). According to him, because vertical thinking is drilling deep into a specific topic, finding holes in one's arguments only helps to clarify why something will never succeed. However, because horizontal thinking allows one to combine different concepts in unusual combinations and leverage different perspectives, this approach would enlighten scholars' visions and help them see a realistic future.

A critical approach and a developmental approach have been recognized to characterize macromarketing's history (Klein 2005). Between the two approaches, Peterson (2006) champions the developmental approach for the advancement of the macromarketing field. As a result, instead of taking a critical approach to existing studies and settled topics, Peterson (2006) recommends macromarketing scholars engage in a developmental approach, which we consider another domain item for this category. Based on the preceding discussion, we identify the following two subcategories to characterize Horizontal Thinking (HT):

i. Thinking broadly across subject matters.

ii. Developmental approach instead of critical approach.

When identifying cases of developmental approach (rather than critical approach), we searched for a holistic approach that expands the related topic by developing and providing new knowledge. Articles with a pure focus on criticizing the past research and/or marketing practices were not included in this 


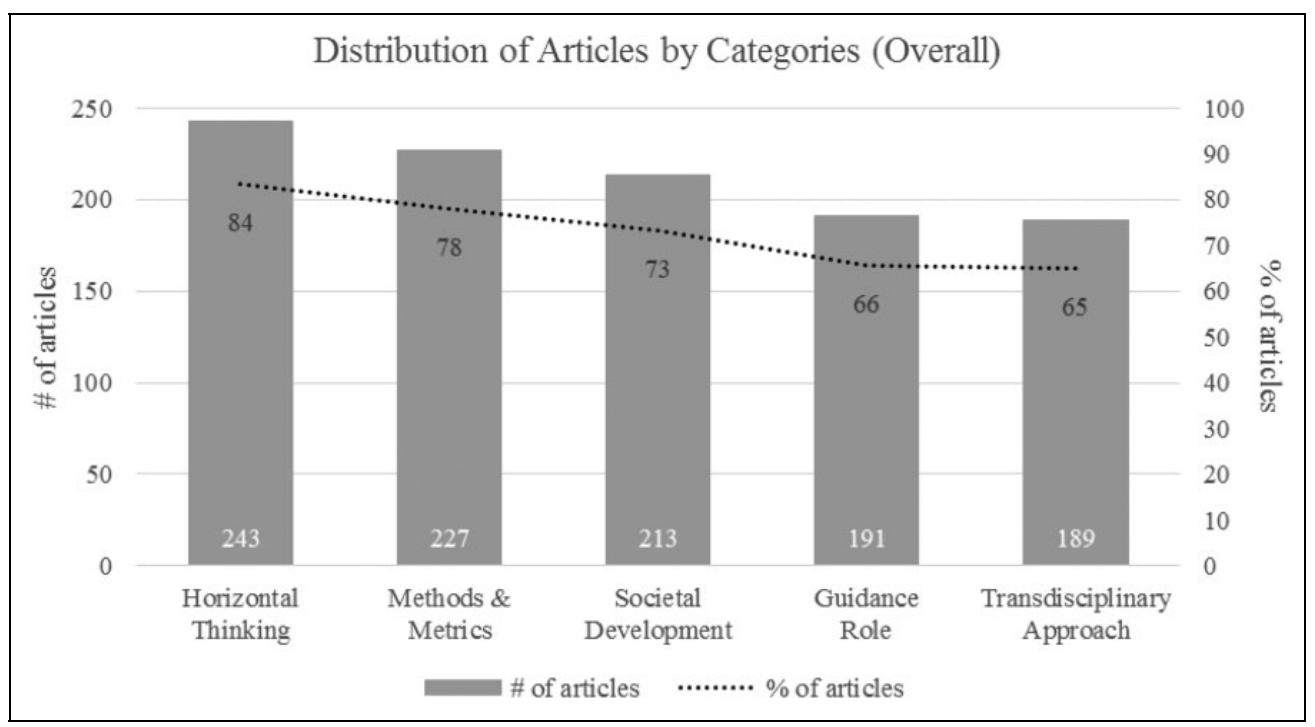

Figure I. Distribution of articles by categories (Overall).

category. Clear suggestions to further explore the related phenomenon, explicit implications of the research findings, and/or engagement in further dialogue with different parties within the topic of interest were some of the clues that helped us identify fitting cases. With respect to the second subcategory, we searched for evidence of an evaluation of different perspectives related to a particular topic and/or a holistic grasp of the issue at hand. For example, if the researched issue delves deeply into details within the same category or domain, the article was not included. However, if the topic and related causes or effects were considered from several aspects and fields, the article was considered a successful fit to the criterion.

\section{Results}

Before going into the detailed results of each category, we present the overall findings (see Figure 1). The results suggest that the articles published in the $J M K$ between 2008 and 2019 are, to a large extent, in line with the visions and recommendations of Fisk (2006) and Peterson (2006).

More specifically, as one can see in Figure 1, recommendations with respect to Horizontal Thinking-HT have been fulfilled by $84 \%$ (243/291) of the articles, followed by recommendations related to Methods and Metrics-MM (78\%; 227/291), Societal Development-SD (73\%; 213/291), Guidance Role-GR $(66 \% ; 191 / 291)$, and Transdiciplinary Approach-TA $(65 \%$; 189/291). One example for each category is provided in Table 5. The examples illustrate how an article fulfills the requirements of a particular category/ subcategory.

\section{Societal Development}

We are pleased to report that our discipline has made a strong commitment to focus on the unifying idea of societal development. The content analysis of 291 articles appearing in the JMK from 2008 to 2019 reveals that a great majority (73\%) of the articles carry a SD-focus. This large percentage is important; it shows how uniquely our discipline has been positioned to demonstrate the tremendous potential of marketing in any society in the future.

This finding also means that about $27 \%$ of the articles lack a SD-focus, and cover topics such as branding, advertising, and marketing history with a commercial perspective (without providing much discussion related to their contributions to $\mathrm{SD}$ ). Please note that the articles we classified within the $27 \%$ (i.e., those with a non-SD-focus) are still relevant to the macromarketing domain, make important contributions to the field, and therefore, were rightfully published in the $J M K$. Nevertheless, these articles can be considered as having a relatively low focus on SD (as described in the previous section). For example, articles dealing with marketing history make important contributions to macromarketing scholarship. However, some of these historical analyses are not considered to have a SDfocus as they do not offer insights regarding SD and/or any of its subcategories. Moreover, during the assessment of SDfocus, we have excluded certain articles if they have a managerial focus with low/no SD-impact discussion, an historical focus without any societal implications or insights, or a strategy (e.g., branding) focus discussing mainly micro (managerial) implications or macro (cultural) implications but not through SD lenses. Please note that the inclusion (exclusion) decision is not based on the topic of the study, but on whether the topic was studied and discussed with (without) a SD-focus in mind. We noted above, for example, that certain branding-related articles were not considered to have a SD-focus. However, there are branding studies that can be considered successful executions of the SD perspective. Conejo and Wooliscroft (2014), for instance, focus on SD by reconceptualizing brands as semiotic marketing systems that generate value for direct and indirect participants, society, and the broader environment beyond a mere profit-seeking objective of the marketing activity. The 


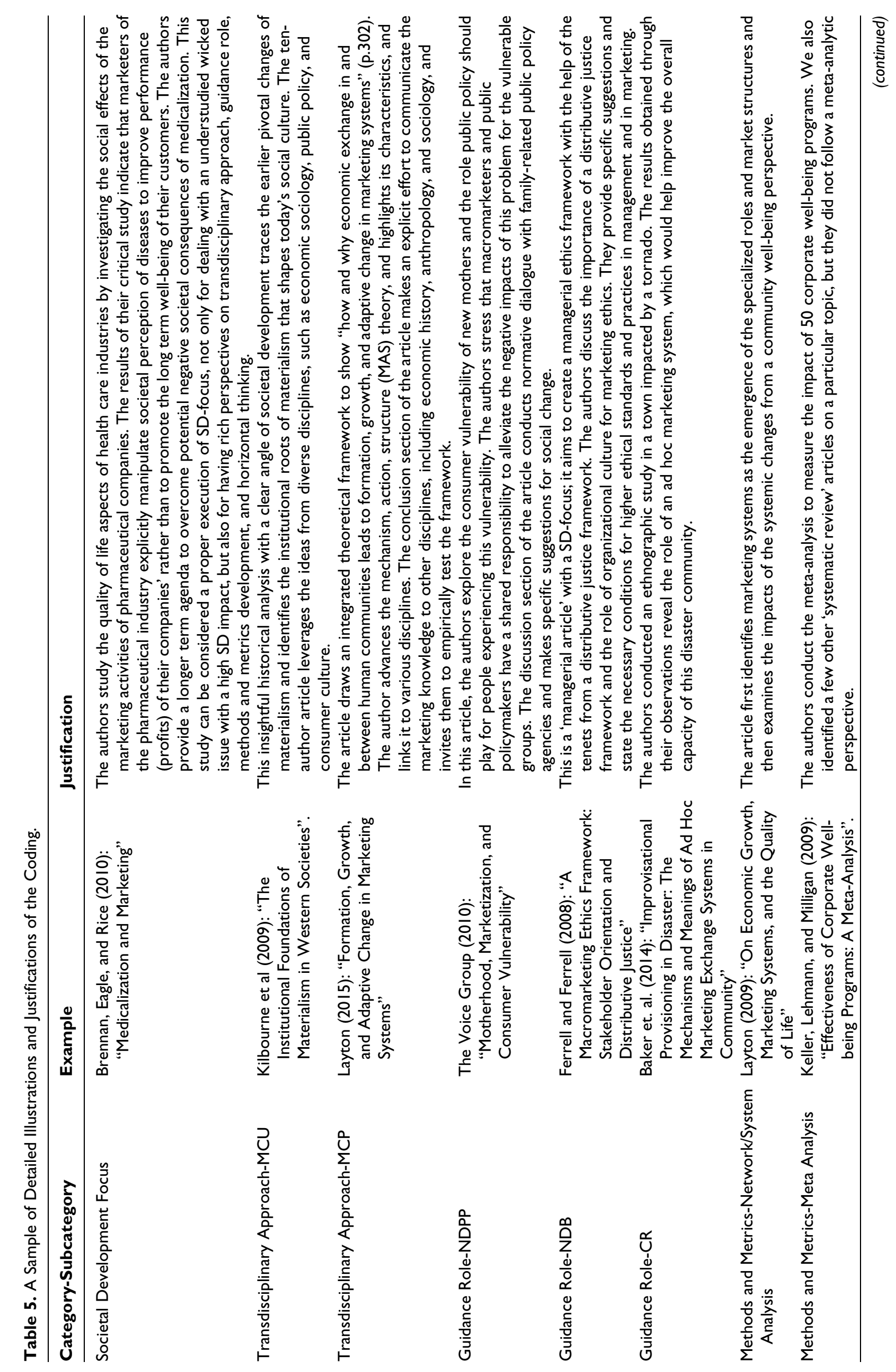




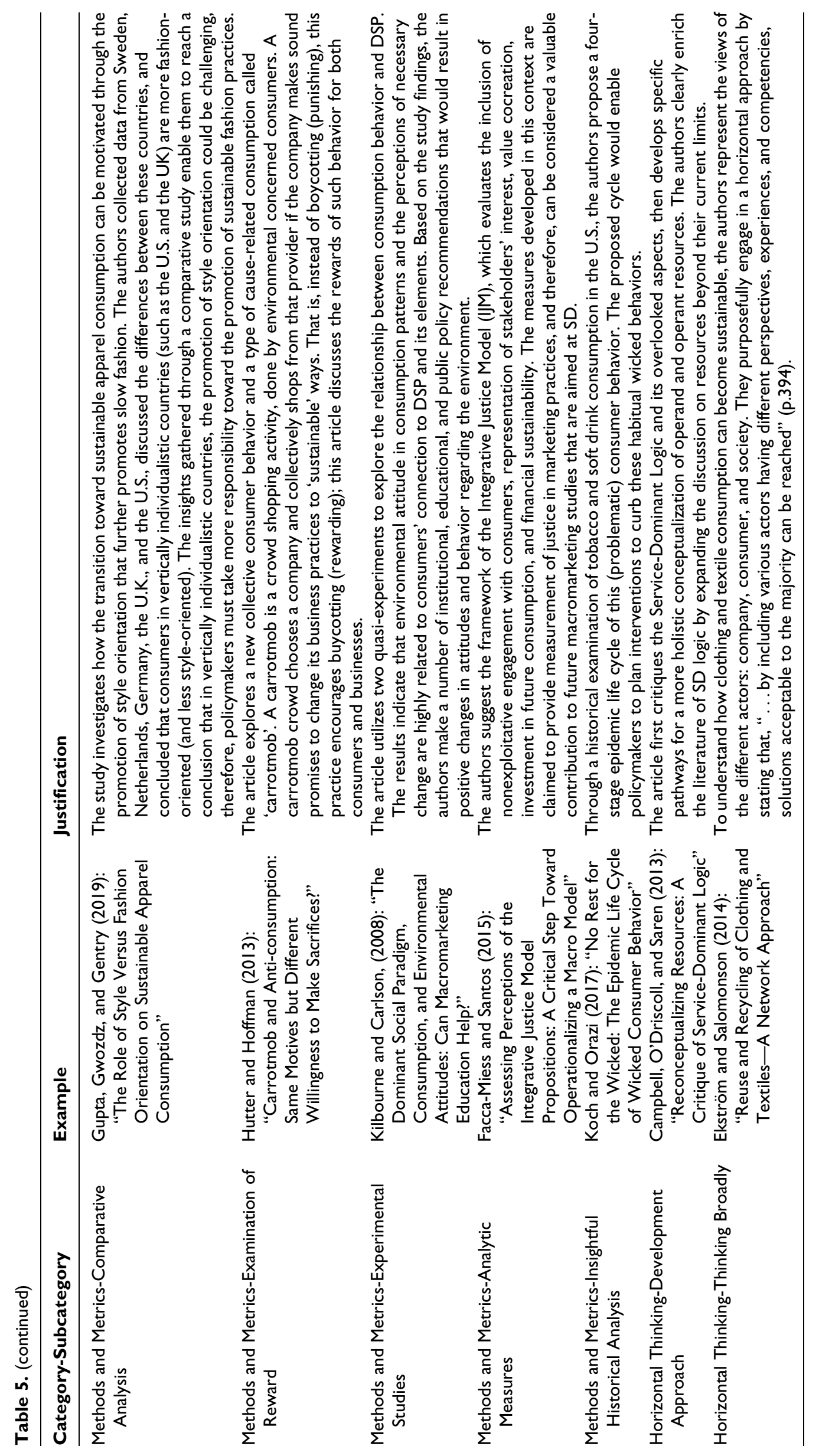




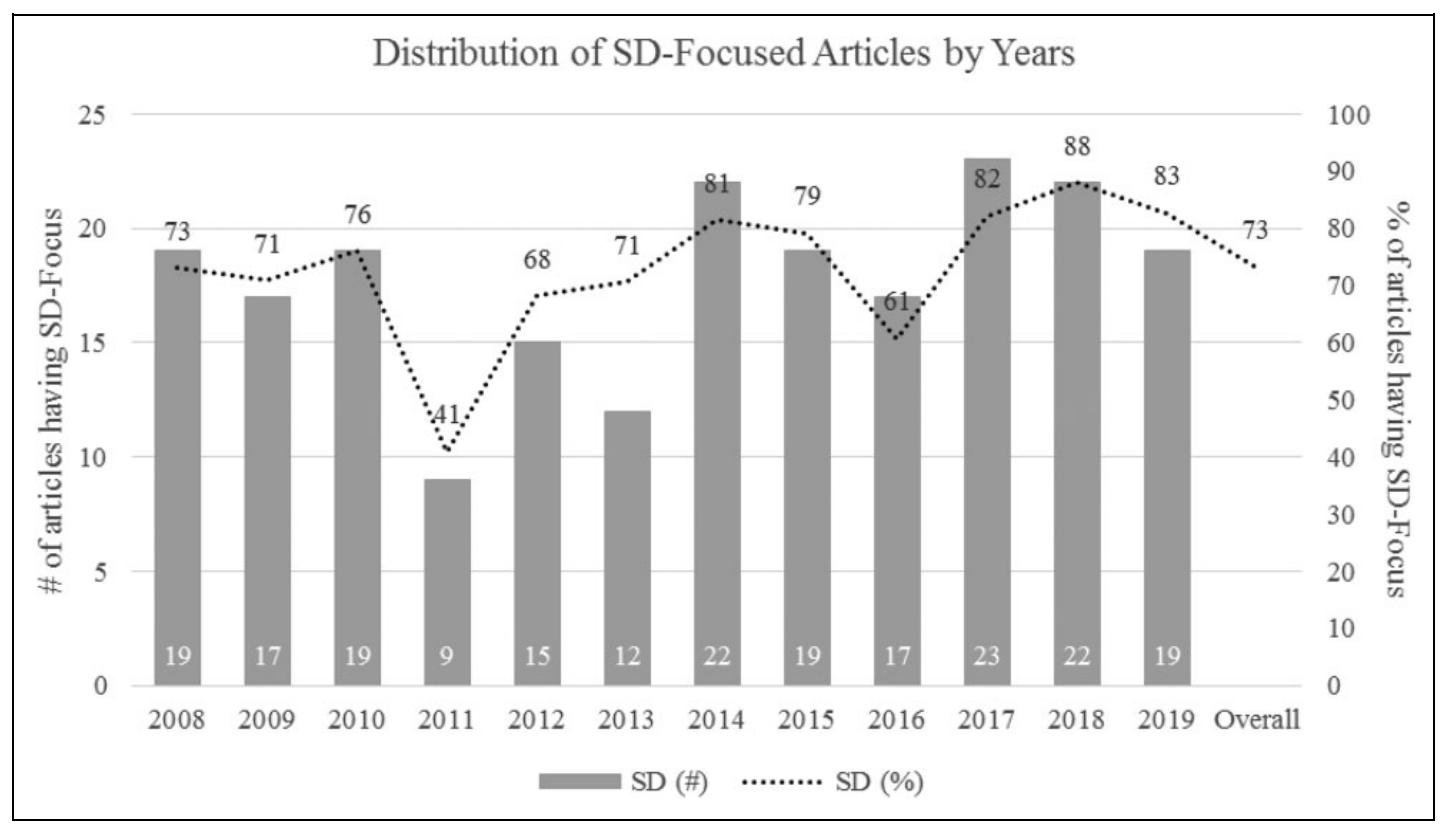

Figure 2. Distribution of societal development (SD)-focused articles by years (2008-2019).

authors predominantly acknowledge socio-environmental issues for justification of this reconceptualization.

As seen in Figure 2, during the twelve-year period the percentage of SD-focused articles fluctuates, with a considerable decline in 2011 and a slight rise in 2014, 2017, and 2018. Interestingly, the starting point of 2008 issues with a $73 \%$ SD-focus, which is the same as the average SD-focus observed between 2008 and 2019. The drop in SD-focus in 2011 can be traced back to the heavy content on historical analysis, including a special issue in that particular year. At the same time, special issues on the subcategories of SD increased the frequency of observations. For example, the 2014 issues focused on poverty, quality of life, vulnerable consumer groups, ethical consumption, subsistence markets, and sustainability. The 2017 issues mainly included topics such as changing tastes and preferences in consumption, alternative economies, and macrosocial marketing. The issues of 2017 , which are the highest contributor to SD-focus (a total of 23 articles having SD-focus) also cover the highest rate of sustainability-related articles (52\%). Another year with high SD content is 2018 . The articles that appeared in 2018 issues mainly consist of topics that deal with marketing systems, market change, resistance to market change, influences on market behavior, and marketing systems' contributions to society.

One important observation is that almost half the SDfocused articles studied well-being and quality of life-related issues (Figure 3). In other words, of the 213 SD-focused articles reviewed, 96 of them $(45 \%)$ were classified within this subcategory. The least investigated domains of SD were ethics (21 articles; $10 \%$ ), health (23 articles; $11 \%$ ), food and agriculture (23 articles; $11 \%$ ), and poverty (29 articles; $14 \%$ ).

We also noticed that certain types of research orientations and approaches are more likely to address the idea of SD as advocated by F\&P. For example, empirical investigations that involve marketing and economic systems (such as food networks, bartering systems, and religion-based economies) can be viewed as better matches to the expectations/recommendations of F\&P, as these articles were initiated as a response to societal problems such as poverty, stigmatization, or food waste. Examination of macrosocial marketing programs or practices is another one of these cases; this research stream is initiated to address wicked problems such as smoking, alcohol, obesity, and gambling.

\section{Transdisciplinary Approach}

Fisk (2006) envisions a future for macromarketing that has active communication with different disciplines. As a first step in this direction, he recommends macromarketers "apply knowledge developed elsewhere to macromarketing issues" (p. 216). We label this recommendation Multidisciplinary Communication by Utilizing Knowledge from Other Disciplines (MCU). In addition to utilizing the knowledge generated in other disciplines, he urges macromarketers to "aggressively communicate existing macromarketing knowledge" with external parties (p. 216). We label this recommendation Multidisciplinary Communication by Providing Knowledge to Other Disciplines (MCP).

While assessing the existence of MCU, we observed that most of the macromarketing articles relied on theories from psychology, sociology, social psychology, cultural studies, economics, finance, sociology, social anthropology, gender studies, philosophy, urbanization, ecology and environmental studies, history, political science, organizational behavior, education, and law. We excluded articles that mainly utilize theoretical frameworks within marketing. 


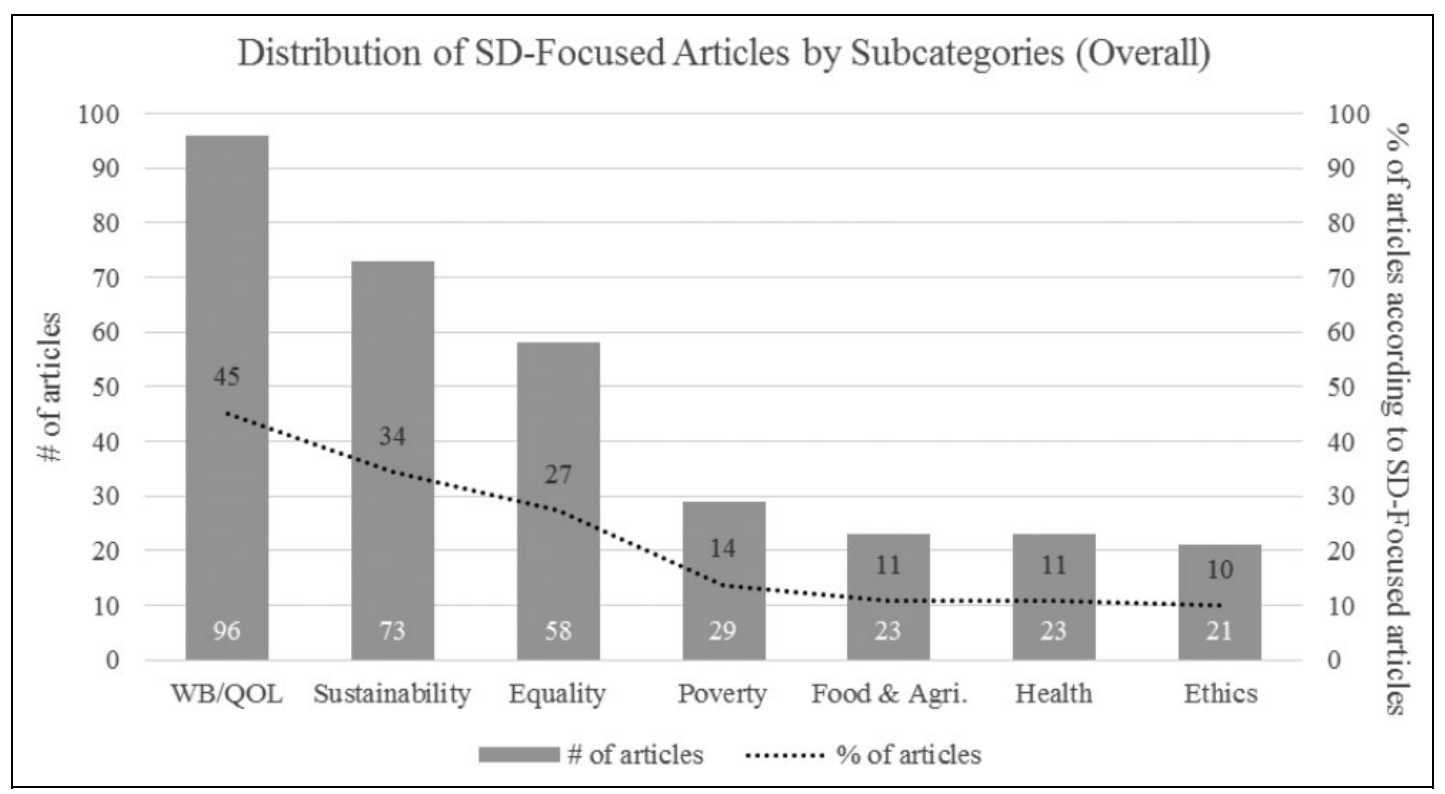

Figure 3. Distribution of SD-focused articles by subcategories (overall).

Articles that fulfilled the expectations with respect to MCP are the ones that had direct communication and reference to another discipline. That is, we sought cases in which the authors made explicit attempts to communicate the outcomes of their article/study with other (nonmarketing) scholars. Disciplines that are explicitly communicated by the $J M K$ articles include organizational behavior, urban planning, economics, environmental sciences, environmental and resource economics, political science, chemical and environmental engineering, economic history, sociology, and anthropology. We excluded articles that do not make explicit attempts to connect their findings/arguments to other (nonmarketing) disciplines and/or do not make future research suggestions for nonmarketing scholars.

Overall, the content analysis revealed that of the 291 articles reviewed, 73 of them were classified as $\mathrm{MCP}$, whereas 173 of them were classified as MCU. As seen in Figure 4, the MCU subcategory has been stable over the years, with only slight fluctuations. One important observation here is the discrepancy between MCU and MCP, which would mean that the articles published during the investigation period have paid relatively low attention to the communication of the macromarketing knowledge to other disciplines. One may argue that the low attention paid to MCP can be a conscious choice of the authors. That is, the authors may deliberately prefer to develop and finetune the newly generated macromarketing knowledge within their own domain before communicating it to other disciplines. The other observation is the widening gap between MCU and MCP over time. Initially (e.g., in the year 2009), we observed relatively similar figures between MCP (15 out of 24) and MCU (17 out of 24). However, the difference between MCP and MCU has widened in time. In fact, regression analysis on the MCP data suggests that the decreasing trend in Figure 4 is statistically significant at the 0.05 level. As an extreme case, for example, issues of 2017 show a drastic drop to almost zero for MCP. On a positive note, our findings suggest that although the first half of the articles (i.e., articles published between 2008 and 2013) scored relatively low on Societal Development (SD), these articles made more attempts to communicate macromarketing knowledge to other disciplines.

In addition to the MCU and MCP approaches, Peterson (2006) made specific calls for "transdisciplinary work". Citing from George Fisk's 30th Macromarketing Conference Speech (Fisk 2005), he points out that true transdisciplinary work should involve an ample number of researchers from a variety of disciplines: "... working with researchers composed of ten or more researchers from other fields" (p.247). Our content analysis revealed that while F\&P's call was not exactly heeded because there was no article with a collective heterogeneous group of more than three researchers (i.e., no article that involves more than three scholars from both marketing and nonmarketing); there was, however, some degree of inter/multi-disciplinary collaboration. As we did the coding for this category, we considered the authors' last professional positions/affiliations to categorize them as either marketers or nonmarketers. Disciplines beyond marketing and macromarketing with which collaboration occurred include management, communication studies, sociology, theology, international affairs, psychology, economics, finance, anthropology, and public administration. As a result, the 'Collaboration with Researchers from Other Disciplines' (CRD) subcategory was the least observed (19\%) in the Transdisciplinary Approach category. Furthermore, during the coding, we realized that a total of eight articles (out of 291) were written entirely by nonmarketing scholars. Because these articles were written by researchers from a single discipline (e.g., all the authors of a particular article are from sociology), they were excluded from the category. Nevertheless, we affirm that 




Figure 4. Distribution of transdisiplinary approach (TA): MCP, MCU and collaboration by years.

the $J M K$ is a valued publication-target for researchers from other disciplines.

\section{Methods and Metrics}

As one can see in the Categories section of this paper, F\&P raise a number of concerns and provide a rich list of recommendations with respect to the methodological aspects of macromarketing scholarship. Based on their arguments, we identified a total of eight subcategories. The results indicate $78 \%$ of 291 articles correspond to at least one of the recommended fields. The following paragraphs examine the results of each subcategory.

The first subcategory is 'Network analysis/marketing system analysis to show long range consequences'. Fisk (2006) points out the importance of marketing systems analysis. During our content analysis, we searched for market analyses with a frame of actors and networks. We excluded articles if they examine marketing system topics but focus mainly on a particular actor rather than interconnected actors/networks. The findings suggest that Marketing Systems/Network Analysis is in 94 articles ( $41 \%$ within the MM category), making this subcategory the most fulfilled methods-related recommendation of F\&P. This relatively high occurrence (32\% among all papers) is a strong indication for the network/system-level analysis to which our discipline has been committed.

Based on F\&P, the second subcategory is 'Meta-analysis of existing studies'. Fisk (2006) points out the importance of leveraging from meta-analysis studies so that macromarketers can have a higher level of dialogue with a larger audience (such as other disciplines, public policy, and businesses). A metaanalysis can also be an excellent resource of new and valuable research ideas (Fisk, 2006). Our results, however, point out the dearth of meta-analysis in the discipline, with only one article out of 291.

The third subcategory is 'Comparative analysis of different nations'. Fisk (2006) criticizes the macromarketing literature for its focus on particular population groups and for offering few comparative analyses between different nations' populations. During our assessment of this subcategory, we searched for articles that provide comparison between two or more countries. We excluded articles that provide simple and undetailed comparisons of different country contexts in the literature review and studies conducted in a single (country) context or in multiple countries, not with the purpose of comparison but to increase sample size and variation in the sample. The results suggest that a very small number of articles $(26 ; 9 \%)$ are concerned with the comparative analysis of different nations. Moreover, the great majority of comparative studies focus on investigating the differences between similar nations. That is, among the 26 articles, only three of them are based on comparisons between developed and developing countries ( $1 \%$ of all articles).

The next subcategory we identified and analyzed is the 'Developed versus developing country context'. Peterson (2006) argues that one way to differentiate macromarketing from other marketing-and-society domains (such as from the International Society of Marketing and Development or ISMD) is through conducting studies in developing and developed country contexts. He further argues that studying SD in developed nations would yield valuable insights for other contexts because these countries have already made important progress on sustainability, and therefore, their experiences can be beneficial for other countries. Among the articles we reviewed (291), 214 of them have a particular (developing or developed) country context. The other 77 articles are either theoretical/ 
conceptual with no specified country context or conducted within mixed (developed and developing country) contexts.

Our context analysis reveals that a total of 127 articles are based on the developed country context. In other words, about $59 \%$ of them (127 out of 214) solely report results from developed country contexts. Over the period of our investigation, this number has fluctuated from a minimum ratio of $20 \%$ (in 2012 ) to a maximum ratio of $85 \%$ (in 2013). Among the articles conducted within a developed country context, the ones with a U.S.-context have the highest share with $41 \%$, followed by Australia with $11 \%$, UK with $6 \%$, Germany with $5 \%$, and all others with $40 \%$. When the numbers for all European Union countries are aggregated, they have a share of $40 \%$ (similar to the share of U.S.-based studies). With respect to developing country contexts (which represent $41 \%$ of the articles with a country context), China has been the most studied country with a $21 \%$ share, followed by Vietnam with $15 \%$, India with $10 \%$, and Turkey with $7 \%$. This figure is only $11 \%$ for all of Africa.

The fifth subcategory, 'Examination of the role of reward in behavior change', is a suggestion by Fisk (2006); he points out the "dearth of research on trade-off rewards for shifting to more sustainable consumption practices" (p. 217). Fisk (2006) claims that rewards are more effective than penalties in changing buyers' (sustainable consumption) behavior. In the content analysis, we merged sustainable consumption and SD-focused articles within this subcategory and searched for cases that explicate the role of reward to succeed for sustainability and SD. Studies that lack a focus on reward or have a 'penalty' based approach (while examining behavior change) were excluded from this subcategory. The results indicate that only 12 out of 291 articles (4\%) satisfy this condition.

The sixth subcategory, 'Experimental studies to delineate boundaries of consumption behavior', is also a suggestion by Fisk (2006) to extend the macromarketing knowledge beyond its current boundaries. Classification of studies under this category is rather straightforward. We simply sought studies that include experimental designs. Out of 291 reviewed articles, there were only three experimental studies (1\%). As one can imagine, this subtheme is one of the least fulfilled visions of George Fisk.

The seventh methods-related suggestion is 'Development and adaptation of shared analytic measures, performance standards or new terminologies'. Fisk (2006) made this recommendation so that macromarketing scholars would become more familiar with cognate disciplines and communicate their scholarship in a multidisciplined environment. For the assessment of this subcategory, we searched for articles that provide new/ enhanced analytic measures, performance standards, and terminologies. Out of 291 articles, 39 studies (13\%) developed shared analytic measures, performance standards, or terminologies. All the articles published in the first issue of 2016, a special issue on Research Methodologies for Macromarketing, successfully fulfilled the requirements of this category.

The eighth subcategory is 'Insightful historical analysis.' Peterson (2006) argues for the need for historical analysis that contributes to the current efforts of SD. In our assessment we selected pure historical analysis articles that provide insights or historical analyses that compare the past, present, and future. We excluded studies that conduct historical analysis with a descriptive approach and those that do not provide insights for the advancement of the topic of interest. Out of 291 articles, 64 (22\%) fulfilled the expectations of this category.

\section{Guidance Role}

Fisk (2006) suggests that the macromarketing discipline must have a guidance role by "asserting our knowledge to advise and guide government and business policymakers toward the most effective business and public policy" (p.215-216). Similarly, Peterson (2006) stresses the importance of the guidance role by suggesting a specific "implications for societal development" section in the JMK's articles (p. 248). Based on these views, we initially analyzed the articles on the extent to which they state societal implications and apply normative dialogue to public policymakers and businesses. Assessment of the criteria 'Normative Dialogue with Public Policy' (NDPP) and 'Normative Dialogue with Business' (NDB) was quite straightforward; we searched for directive tones with respect to the societal implications stated in the articles. We included, in both criteria, the specific directions that the authors provide to the readers (which have directive verbs, such as should, need to, ought to, must, have to). Studies that use 'suggestive language' (such as may, might, can) in their implications sections were not considered; this fulfills the Guidance Role (GR), even though the studies aim to open a dialogue between macromarketing and other stakeholders. In addition, we excluded studies that merely present the idea of their research subjects/participants without providing interpretations and/or discussions, and studies that provide general implications of the main results without suggesting any particular course of action and/or addressing any specific accountable party.

As explained earlier, in addition to NDPP and NDB, a third dimension (Creating recognition and awareness about the provisioning role of marketing for a sustainable future and societal development or CR) is included within the GR category. This subcategory is concerned with the guidance role macromarketing scholarship can play within other disciplines. While assessing, we searched for a clear declaration that the authors juxtapose the studied topic and the macromarketing field as a main contributor to the alleviation efforts of a particular wicked issue. Articles that lack such dialogue were excluded.

Based on the above criteria, the content analysis revealed an almost equal number of observations for NDPP and NDB, 92 and 88 respectively. Furthermore, as seen in Figure 5, for most of the investigation period the NDPP and NDB scores were similar.

Overall, we can say that the GR has been accomplished through approximately 66\% (191 out of 291) of the articles (see Figure 6). Guidance Role was most established in the year 2018 , as $88 \%$ of the articles carried it (CR-role being the main contributor). The topics of 2018 include marketing systems, market change and resistance to market change, influences on market behavior, and marketing systems' contributions to society. 


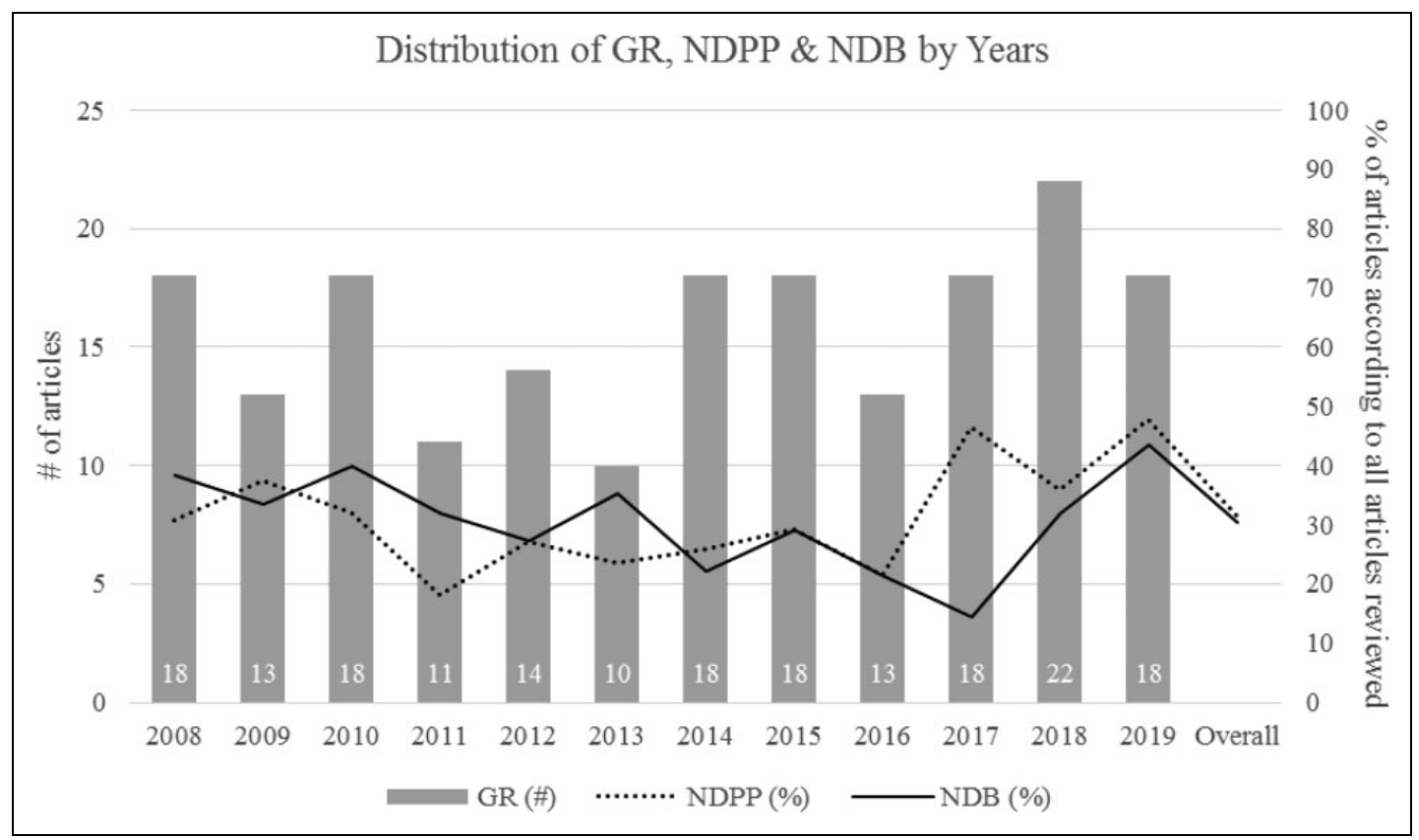

Figure 5. Distribution of guidance role (GR), normative dialog with public policy (NDPP \& normative dialog with business (NDB) by years.

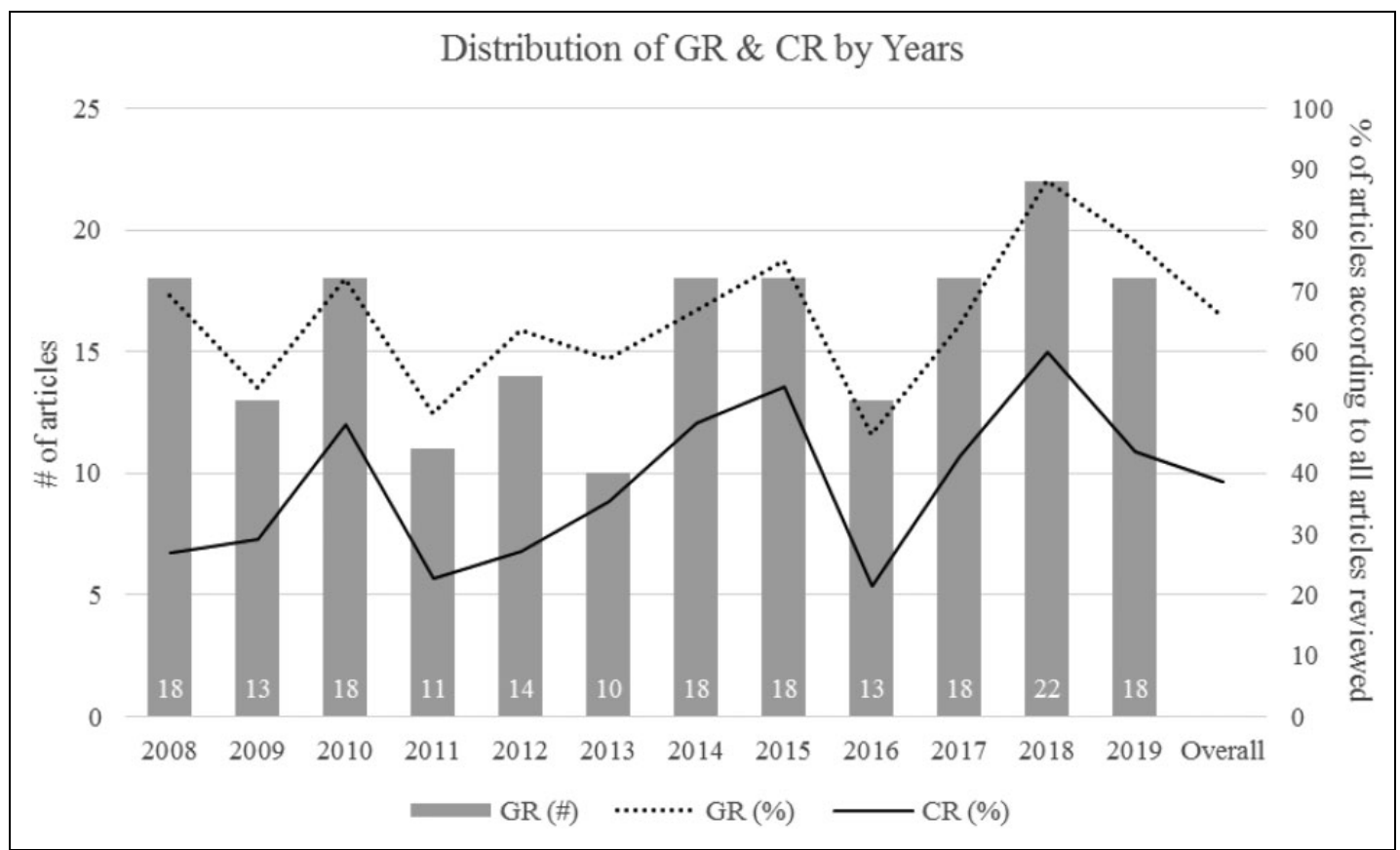

Figure 6. Distribution of guidance role (GR) \& creation awareness about provisioning role of marketing for societal development (CR) by years.

\section{Horizontal Thinking}

As stated earlier, Peterson (2006, p. 247) champions the developmental approach over the critical approach because the developmental approach not only defines the problem but also shows the "way out of the current mess" (p. 247). He refers to Thomas Bernett's (2004) book "The Pentagon's New Map" where the author explains how vertical thinking - which is basically "drilling down deep in a subject matter" - only explains failure (Peterson 2006, p.247). Horizontal thinking, on the other hand, which is basically "thinking broadly across subject matters", is a means to "see a future unfolding realistic stage" and can be achieved by taking advantage of combining divergent concepts in nonhabitual combinations (Peterson 2006, p.248). Along similar lines, Fisk (2006, p.214) implicitly points out a similar idea by stating that benefit-cost assessments must be conducted in macromarketing studies to be able to see the spillover effects and long-range consequences. 




Figure 7. Distribution of horizontal thinking $(\mathrm{HT})$, developmental approach (DA) \& thinking broadly (TB) by years.

From the above discussion, we constructed the theme Horizontal Thinking (HT) based on two subcategories: Developmental Approach (DA) and Thinking Broadly (TB). The DA subcategory excluded articles that simply describe a relationship but do not indicate practical implications for improvement and critical studies that do not suggest any possible solution to the problem they investigated. The TB subcategory excluded articles that integrate a limited number of stakeholders into the analysis, discuss only the positive sides of a controversial issue (even though there may also be negative aspects), and study a microlevel phenomenon without specifying and discussing its meso- and/or macrolevel implications.

The content analysis reveals that, as compared to the other recommendations, the HT (with its subcategories) has been the one most often followed. More specifically, of the 291 articles analyzed, we observe the existence of HT in $83.5 \%$ (243/291). This ratio reflects the articles that are classified under either one or both of two subthemes. More specifically, the percentage of articles that fit into both subcategories is $46.4 \%$; into the DA subcategory, $17.9 \%$; and the HT subcategory, $19.2 \%$.

As one can see in Figure 7, the DA subcategory was mostly stable over the twelve years, but it fluctuated notably between 2013 and 2015. It reached its peak point in 2013 (88\%), the year that had issues on globalization of marketing ideology, macromarketing implications of corporate sponsorship, the ethics of social marketing, food marketing systems, anti-consumption, adoption of renewable energy systems, the evolution of brand meaning in China, a critique of service-dominant logic, and macromarketing ethics and justice in regulated businesses and government policies. However, in 2015, the figure drops to $50 \%$. The TB subcategory also had a relatively stable progress over the years, except for the year of 2014 with its highest occurrence at $81 \%$, and the year 2008 with its lowest occurrence at $50 \%$.

\section{Discussion}

The objective of this study was to conduct a thorough content analysis to examine the extent to which macromarketing scholars have responded to the calls and recommendations made by F\&P in their 2006 SAI articles. We believe that our analysis depicts an informed picture of the past twelve years of the scholarship published in the $J M K$, and provides insights as well as possible research directions for macromarketers. In this section, we discuss our findings and make recommendations for future research.

First, macromarketers can be proud of the SD-focused body of work they have produced since the SAI! More specifically, the findings from this analysis reveal that almost three in four articles $(73 \%)$ have a SD-focus. Although the content and extent of SD-focus (e.g., well-being, sustainability, equality, etc.) vary from article to article and from issue to issue, one can say that a SD-focus has been prevalent during the past twelve years. The other quarter (approximately) of the articles, which are also valuable to the field, may not have a SD-focus, but for the most part, they, too, provide meso- (network) and/or macro- (political and/or socio-sociocultural) level implications of their studies. Throughout the twelve years we have not observed a sharp increase in the share of SD-focused studies; however, because our analysis does not include articles before 2008, we are not able to make a firm conclusion about whether the call for a SD-focus made a difference. Future research that investigates the phenomenon prior to 2008 may provide more realistic comparisons on this matter.

Furthermore, our content analysis revealed that, of the seven subcategories of the SD-focus, QOL/Well-being was the most frequently studied. More specifically, approximately one third (33\%) of all the articles reviewed dealt with QOL/Well-being aspects of SD. Unlike other domains of SD, the focus on QOL/ 
Well-being issues has been quite stable over the years (on average, eight articles per year). As a result, a considerable amount of literature has been accumulated just within the $J M K$ domain. Therefore, potential future studies could investigate not only its dominant presence within the $J M K$, but also its evolution with respect to content (e.g., whether and how the studied life-domains were in line with the global societal trends), context (e.g., development stages of the markets), level of analysis (e.g., micro, meso, or macro), methodological approaches (e.g., qualitative, quantitative inquiries, and developments with respect to its measurements), and so on. Drenten and McManus (2016) is an example of such an approach: the authors provided an in-depth analysis of the religion-related research that appeared in the $J M K$ between 1981 and 2014.

Moreover, our content analyses have revealed the existence of certain understudied and underrepresented SD domains, such as ethics, health, food and agriculture, and poverty. These four understudied areas are crucial because they are related to the very basic aspects of humanity: the need for fairness and the maintenance of a life with optimized physical conditions, nourishment, and subsistence. Interestingly, these areas are among the topics that shape most of the debates around the current virus pandemic. Unethical business practices that threaten sustainability, inefficiencies in health systems to provide basic preventive health care for all, access to proper food and nutrition to boost one's immune system, and the deficiencies in the current market systems in terms of the distribution of resources based on equity and equality are likely to be important topics that scholars and policymakers will face in the aftermath of the pandemic. As the future of markets changes, macromarketers may spend more time and effort studying the aforementioned underrepresented SD-domains.

Special issues on health, food/agriculture, and ethics/equity can provide platforms for macromarketers to contribute to upcoming discussions on how to address the problems that led to the present worldwide pandemic crisis. Business ethics in general, and marketing ethics in particular, are likely to face novel challenges as newer forms of IT-based networks and systems dominate markets and marketing. Future macromarketing ethics studies can delineate the dyadic and networkbased problems of these new technologies as well as offer solutions.

In many countries, food security is handled at the national level; however, during severe conditions (such as the global ecological, drought, or pandemic crises) national governments may be overwhelmed and may be unable to provide timely assistance to their citizens. It is important to start studying the problems of the global food supply systems so that the system can ensure food sufficiency during emergency food crisis conditions.

Food distribution networks in underdeveloped and developing countries were among the first major topics of macromarketing (e.g., Harrison et al. 1974; Kumcu and Kumcu 1987; Slater 1965). In the aftermath of the current global crisis, macromarketers will need to go back to the origins of the discipline and study the effectiveness of national, as well as global, food distribution systems. The lack of access to a particular food (which many people may be experiencing for the first time in their lives) is exacerbated by the threat of not having any source of income or access to food at all. Close to one billion people around the world find themselves in this latter situation as they face the additional (poverty) threat of a global pandemic (Foodtank 2020). Therefore, another crucial area for macromarketers to investigate is the issue of food security among people experiencing poverty. Our analysis indicates that many of these areas (e.g., ethics, food, agriculture, poverty) were among the least studied dimensions of SD over the last twelve years. However, these are also the areas in which macromarketers are equipped to make contributions. This void can be filled by encouraging macromarketers to engage in research on these issues and via the formation of thematic macromarketing conferences and/or special issues.

As noted, macromarketers have been successful in focusing on the domains of SD in their research. However, for this focus to have an impact on societies, our discipline must also adopt the TA. Peterson (2006) argues that taking a SD-focus as a transdiscipline would yield better outcomes for the future of societies (p. 247). Our content analysis shows that, among the five categories, TA has the lowest rate of adoption (65\%). This finding is noteworthy because TA and SD-focus are essential for the existence of one another. In other words, the SD-focus can increase the impact of the macromarketing discipline if it is coupled with TA. Furthermore, our analysis indicates that the two subcategories that are crucial for external communication, MCP and CRD, appear even more problematic: in only $25 \%$ of the articles did the authors make an explicit effort to communicate their research findings to other disciplines, and only $12 \%$ of the articles involved collaborations with scholars from other disciplines.

As noted earlier, we captured the MCP aspect of TA based on whether the authors of the article made explicit attempts to address their findings/results to particular fields (outside of macromarketing). To provide more textured insights into the issues surrounding TA, we conducted a post-hoc citation analysis. Specifically, through citation analysis, we identified whether and to what extent highly cited $J M K$ articles have been recognized (i.e., cited) outside of macromarketing and mainstream business outlets. To this end, the 10 most-cited articles from 2008 to 2018 (inclusive) were set as a representative sample because they include a sufficient number of citations to make inferences. The number of citations that articles had was listed on the research article's official $J M K$ page (as of June 21, 2020). Then, citations of the top 10 list were investigated through the domain of citations, based on the following three categories: (I) cited in the Journal of Macromarketing, (II) cited in other marketing and management outlets, and (III) cited in other domains. Specifically, if an article was cited by any marketing or management related journal or book in domains such as marketing theory, consumer research, or business management research, it was coded under the (II) category. If the citing source's title was not related to macromarketing, marketing, or business, yet belonged to other 
specific domains (such as food and agriculture, tourism, or psychology, etc), it was coded under (III). Also, if the citing platform had a very general scope, such as university press of social sciences in general, it was also coded under category (III). The results of the citation analysis are presented in Table 6.

A review of the information provided in Table 6 suggests that all the top-ten cited articles carry a SD-focus. Moreover, most of these SD-focused articles have been heavily cited outside of macromarketing. Three of these articles (Arvidsson 2008; Claudy, Peterson, and O'Driscoll 2013; Thogerson 2010) are particularly significant as most of their citations are from other disciplines, including media, technology, cultural studies, sociology, food, agriculture, tourism, psychology, and energy. Likewise, more than $40 \%$ of the citations of Bonsu and Darmody (2008) and Kozinets, Hemetsberger, and Schau (2008) come from other disciplines. These cases indicate that, although our content analysis reveals an overall drop in our explicit attempts to relate macromarketing knowledge to other disciplines (i.e., a decreasing trend in MCP), there are certainly good examples that go against that trend. These examples, we believe, strengthen the arguments that an improvement in TA is needed to make progress in SD-focus more meaningful.

When it comes to possible improvements on the CRD dimension of TA, motivating macromarketing scholars to engage in a collaborative research is important, but may not be sufficient. They should also be encouraged to invite researchers from the various fields related to their inquiry. To this end, Annual Macromarketing Conferences, for example, can be redesigned to include special sessions that bring together people from different disciplines who are working on the same topics. The conference track chairs can be encouraged to proactively form roundtable sessions and recruit scholars from various disciplines to participate in these roundtable sessions. The JMK can consider special issues based on the transdisciplinary works driven from these conference roundtable discussions.

Our findings indicate that, except for a couple years (e.g., 2011 and 2017), the authors have paid almost equal attention to making suggestions to marketing practitioners and public policymakers. In total, about two thirds (66\%) of all articles engage in one or more aspects of the GR. An interesting observation, however, is the remarkably high occurrence of GR perspectives when articles take the SD-focus. More specifically, although the average GR is found to be $66 \%$, among the articles adopting a SD-focus this figure rises to be $82 \%$. These findings imply that SD-focused studies are more likely to take a GR perspective. Therefore, it is reasonable to expect that when the discipline continues to position itself toward the SD-focus, the potential contribution of our scholarship on business and public policy would also increase.

Both F\&P (and particularly George Fisk) allocated significant parts of their SAI articles to making recommendations regarding the MM issues. As once can see in the previous sections, we identified a number of subdimensions as the domain of this category. The results indicated an overall high fit between the expectations and occurrences for this category (i.e., 78\%). Nevertheless, we believe this finding requires further interpretation. The subcategories we identified from the accounts of F\&P are mutually exclusive. Therefore, even though an article fulfills the requirements of only one of the eight recommendations, the article would still be considered fulfilling the expectations of the MM category. This protocol may explain the high compliance with this recommendation. However, if one examines the number of fitting cases for each subcategory, a different picture surfaces.

Consistent with the overall spirit of macromarketing, we were delighted to observe that a relatively high number of articles $(94 ; 32 \%)$ published in the $J M K$ involve Marketing Systems Analysis (MSA). However, some methodological issues that Fisk (2006) raised as crucial toward achieving a sustainable future have received very little attention from macromarketing researchers. As one can see in Figure 8, only twelve articles provide a framework built upon the rewards for a changed behavior or action. Instead of focusing on penalties and reflecting images of worst-case scenarios, as Fisk (2006) recommended, it may be more beneficial to focus on rewards that lead to SD. While the lack of reward-related studies may appear a shortcoming of the field for now, paying more attention to this type of research can also help in differentiating the discipline.

Another method-related shortcoming comes from a lack of Experimental studies to delineate boundaries of consumption behavior (i.e., only three articles in the last twelve years). As noted earlier, psychology is among the disciplines most utilized by macromarketers. However, experimental studies (a primary method in psychology) are almost nonexistent in the macromarketing scholarship. This reluctance may be related to the fact that experimental designs are generally conducted to investigate microlevel phenomena. Nevertheless, our analysis revealed that, although very few, the microlevel experimental studies can be considered fitting to the domain of macromarketing (and as a result find a place in the $J M K$ ) when they make efforts to relate their results to higher level issues and abstractions (see Attachment A).

Additionally, since publication of the SAI, marketing scholars have occasionally recognized the overlap between behavioral economics and consumer/marketing decision-making (e.g., Bertrand, Mullainathan, and Shafir 2006; Conick 2018; Johnson 2006). Given the recent developments in behavioral economics (e.g., Thaler and Ganser 2015), we believe it is time for macromarketers to use the knowledge generated in behavioral economics and engage more in experimental studies to improve the societal impacts of the marketing work.

Only one article (of 291) carried a meta-analytic perspective, making this subcategory the least fulfilled recommendation of Fisk (2006). However, we believe that as our domain becomes more focused and generates more knowledge within the various subdomains of $\mathrm{SD}$, there will be more opportunities for macromarketers to conduct meta-analyses.

Macromarketing scholars were called to engage in comparative analysis so that more effective and beneficial 


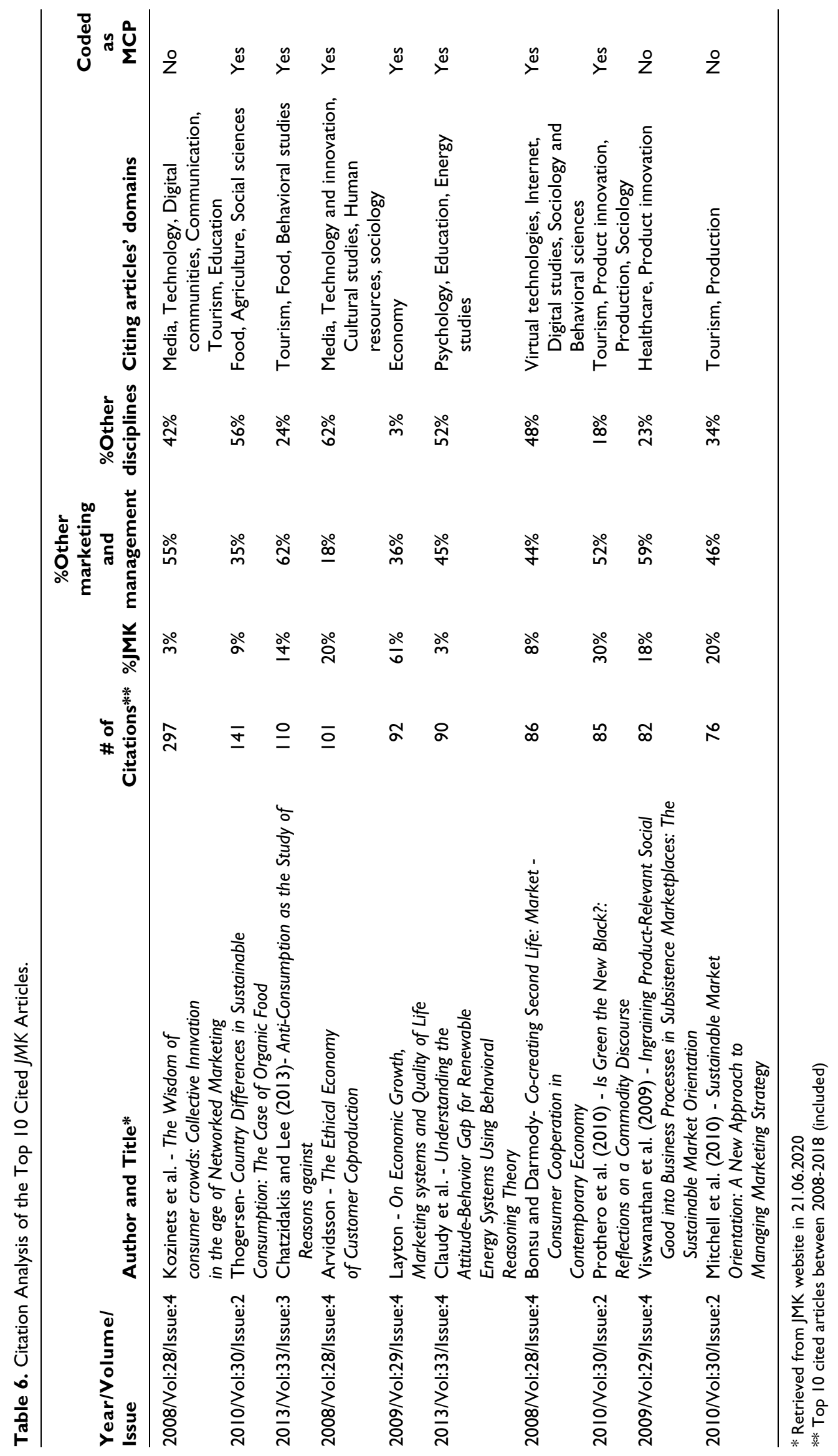






Figure 8. Distribution of articles by subcategories of methods and metrics (MM) (overall).

recommendations could be made to businesses and policymakers. However, our results indicate that only eleven articles (9\%) were based on comparisons of different country contexts. When it comes to studies comparing developed versus developing countries, the figure drops to only three articles (1\%). If macromarketers agree with Fisk (2006) about the importance of conducting comparative analyses, then the reasons behind these low figures may need to be understood. Certain resource, network, or cultural barriers may discourage macromarketing researchers from engaging in comparative studies. Macromarketing leadership can identify these barriers and implement measures and tools to motivate researchers to engage in comparative studies. Considering the diversity of countries from which macromarketers come, opportunities exist to form cross-cultural research teams and projects.

\section{Limitations and Clarifying Remarks}

Before concluding, we would like to clarify a few points regarding our study and recognize the limitations of the findings. As we explained earlier, the content of our assessment had a predetermined frame, which was drawn from the SAI articles of F\&P. The categories we identified are Societal Development focus (SD), Transdisciplinary Approach (TA), Guidance Role (GR), Methods and Metrics Development (MM), and Horizontal Thinking (HT). These categories include a total of 24 subcategories. We would like to state that our intention was not to evaluate and/or criticize the individual articles published in the $J M K$, but to determine where they fit according to our predetermined frame. We acknowledge that the studies may have been designed and the articles written with strengths that are not covered within the aforementioned framework.

Our intention was to take a snapshot of the recent status of the articles published in the $J M K$ and capture the overall tendency of whether the assembled work within the past twelve years has been in accordance with that framework. In other words, the purpose of this review is to demonstrate to what extent the visions and recommendations of F\&P were covered, and to provide an evolutionary retrospective that can serve the future of our discipline. It is plausible to argue that some macromarketing scholars may not have been in agreement with F\&P with respect to the future directions of the macromarketing field, and therefore, may consciously prefer to focus on areas that are outside of this framework.

Furthermore, some of our results may involve certain limitations. For example, we recognize that macromarketing knowledge is not automatically disseminated just because the authors make explicit attempts in their articles to communicate their results to other disciplines. In other words, it is possible that an article may not explicitly attempt to communicate and therefore be excluded in the "Multidisciplinary communication by providing knowledge to other discipline" (MCP) category of the analysis; at the same time, it could be cited highly outside of our discipline. Similarly, the author of an article may make explicit attempts to communicate findings with other disciplines, but the article may not be recognized (cited) by these disciplines. The post-hoc citation analysis that we mentioned earlier offers further insights into the above mentioned issue.

More specifically, the citation analysis we conducted and reported in Table 6 reveals that even though the top-cited JMK article between the years 2008 and 2019 (Kozinets, Hemetsberger, and Schau 2008; with a total of 297 citations) had not made an explicit attempt to communicate the study findings with other disciplines, and hence, was not included in the MCP category in our study, 125 (42\%) of its citations are coming from outside of business. On the other hand, another highly cited article (Layton 2009), which has been classified as having the MCP perspective in our study because the author had made an explicit attempt to communicate the article with other 
disciplines, has only $3 \%$ of its 92 citations coming from outside of mainstream business outlets.

Moreover, the content analysis of our research starts from 2008 (two years after F\&P's call for macromarketers) to allow reasonable time for articles reflecting these recommendations to appear in the $J M K$. Therefore, it does not compare the results with what happened before 2008. Three researchers have ensured an exhaustive content analysis for each original/ research article based on the predetermined checklist. In addition, the $J M K$ is not the sole outlet for macromarketing scholarship. We, for example, did not analyze works published in the Macromarketing Conference Proceedings, nor other journals of interest.

Furthermore, the interpretation of the articles was deliberately limited by a Western approach of perception due to the nature of the academic language being English. While there are differences in the usage of English in the daily lives of native and nonnative speakers as high or low context of communication style, we didn't take these differences into account in order to provide a standardized and parsimonious platform for evaluation. An example for such a case would be the evaluation of 'Normative Dialogue'. While we searched the texts for explicit normative dialogue with a strong communication style via words such as 'should', 'must', and 'have to' (modals of obligation and advice), 'may', 'might', and 'can' were not included in this category. We do, however, acknowledge that context of communication differs from culture to culture.

\section{Conclusion}

George Fisk once said, "the purpose of macromarketing ... is to save the world" (Fisk 2001, p. 121). As the world's ongoing battle with the COVID-19 pandemic continues, this bold mission, once again, points out how valuable the knowledge generated through the macromarketing scholarship (with its focus on the sustainability of markets and society) can be for the survival of humanity. Macromarketing scholarship may have the purpose to 'save the world' - but how? In 2006, the SAI assembled the visions of many prominent macromarketing scholars to provide possible directions to answer this question (Shultz 2006).

"We must focus" was a clear call from Peterson (2006). According to him, a lack of focus in macromarketing had been causing a positioning problem for the field, and the solution would be in the societal development focus (p. 248). "So where do we go from here?" was another concern raised by Fisk (2006, p.218). His call was related to drastic changes in sustainability issues that societies have faced for the last few decades, and to the need for a synergy to work together to solve the sustainability problems of the world. Through a host of specific recommendations, F\&P encouraged macromarketers to make progress in this direction so that macromarketing could fulfill its mission.

Our study aims to provide an evolutionary picture of the discipline over the past twelve years. Overall, the results suggest that the macromarketing scholarship has, to a large extent, responded to the calls of F\&P. However, there are certain areas that require further attention. The Societal Development (SD) focus has increasingly become the overarching theme of the macromarketing scholarship. A great majority of articles published over the past twelve years in the $J M K$ carries a SD-focus. Certain areas within this domain, however, including ethics, health, food/agriculture, and poverty, have been underresearched. Higher degrees of Transdisciplinary Approach (TA), such as active communication of the research findings and the formation of multidisciplinary research teams, would be needed to disseminate the knowledge generated through macromarketing scholarship and to advance the Guidance Role (GR) of the discipline. The utilization of diverse analytic approaches, including meta-analyses, comparative analyses, and experimental designs, would likely pave the road for a higher level of dialog with larger audiences, including other disciplines, public policy, and business. We hope that the recommendations and the calls we have made in this paper will help macromarketing fulfill its mission in the next ten years, until we reach the Golden Anniversary Issue.

\section{Declaration of Conflicting Interests}

The author(s) declared no potential conflicts of interest with respect to the research, authorship, and/or publication of this article.

\section{Funding}

The author(s) received no financial support for the research, authorship, and/or publication of this article.

\section{ORCID iD}

Ahmet Ekici (D) https://orcid.org/0000-0002-5249-1329

\section{References}

Arvidsson, Adam (2008), "The Ethical Economy of Customer Coproduction," Journal of Macromarketing, 28 (4), 326-38

Baker, Stacey Menzel, Ronald Paul Hill, Courtney Nations Baker, and John D. Mittelstaedt (2014), "Improvisational Provisioning in Disaster: The Mechanisms and Meanings of Ad Hoc Marketing Exchange Systems in Community," Journal of Macromarketing, 35 (3), 334-52.

Barnett, Thomas P. M. (2004), The Pentagon's New Map: War and Peace in the Twenty-First Century. New York: G. P. Putnam.

Bertrand, M., S. Mullainathan, and E. Shafir (2006). "Behavioral Economics and Marketing in Aid of Decision Making Among the Poor," Journal of Public Policy \& Marketing, 25 (1), 8-23.

Bonsu, Samuel K. and Aron Darmody (2008), "Co-creating Second Life: Market-Consumer Cooperation in Contemporary Economy," Journal of Macromarketing, 28 (4), 355-68.

Brennan, Ross, Lynne Eagle, and David Rice (2010), "Medicalization and Marketing," Journal of Macromarketing, 30 (1), 8-22.

Campbell, Norah, Aidan O'Driscoll, and Micheal Saren (2013), "Reconceptualizing Resources: A Critique of Service-Dominant Logic," Journal of Macromarketing, 33 (4), 306-21.

Chatzidakis, Andreas and Micheal S. W. Lee (2013), "AntiConsumption as the Study of Reasons against," Journal of Macromarketing, 33 (3), 190-203. 
Claudy, Marius, Mark Peterson, and Aidan O'Driscoll (2013), "Understanding the Attitude-Behavior Gap for Renewable Energy Systems Using Behavioral Reasoning Theory," Journal of Macromarketing, 33 (4), 273-87.

Cohen, Jacob A. (1960), "Coefficient of Agreement for Nominal Scales," Educational and Psychological Measurement, 20 (1), 37-46.

Conejo, Francisco and Ben Wooliscroft (2014), "Brands Defined as Semiotic Marketing Systems,” Journal of Macromarketing, 35 (3), 287-301.

Conick, Hal (2018), "Read This Story to Learn How Behavioral Economics Can Improve Marketing" Accessed August 28, 2020. https://www.ama.org/marketing-news/read-this-story-to-learnhow-behavioral-economics-can-improve-marketing/

Drenten, Jenna and Kristy McManus (2016), "Religion-Related Research in the Journal of Macromarketing, 1981-2014," Journal of Macromarketing, 36 (4), 377-87.

Ekström, Karin M. and Nicklas Salomonson (2014), "Reuse and Recycling of Clothing and Textiles-A Network Approach," Journal of Macromarketing, 34 (3), 383-99.

Facca-Miess, Tina M. and Nicholas J. C. Santos (2015), “Assessing Perceptions of the Integrative Justice Model Propositions: A Critical Step Toward Operationalizing a Macro Model," Journal of Macromarketing, 36 (1), 68-77.

Feng, Guangchao C. (2015), "Mistakes and How to Avoid Mistakes in Using Intercoder Reliability Indices," European Journal of Research Methods for the Behavioral and Social Sciences, 11 (1), 13-22.

Ferrell, O. C. and Linda Ferrell (2008), "A Macromarketing Ethics Framework: Stakeholder Orientation and Distributive Justice," Journal of Macromarketing, 28 (1), 24-32.

Fisk, George (1981), "An Invitation to Participate in Affairs of the Journal of Macromarketing," Journal of Macromarketing, 1 (1), 3-6.

Fisk, George (2001), "Reflections of George Fisk" (from plenary session presentation at the 2001 Macromarketing Conference), Journal of Macromarketing, 21 (2), 121-22.

Fisk, George (2005), "History of Macromarketing Panel," 30th Annual Macromarketing Conference, St. Petersburg, FL, May 29.

Fisk, George (2006), "Envisioning a Future for Macromarketing," Journal of Macromarketing, 26 (2), 214-18.

Foodtank (2020), "How Will Coronavirus Affect Our Food?" Accessed April 7. https://foodtank.com/news/2020/03/how-willcoronavirus-affect-our-food-a-dispatch-from-mexico/

Government of New Brunswick (GNB) (2020), "What is Social Development? GNB, Economic and Social Inclusion Corporation," Accessed June 20. https://www2.gnb.ca/content/gnb/en/depart ments/esic/overview/content/what_is_social_development.html

Gupta, Shipra, Wencke Gwozdz, and James Gentry (2019), “The Role of Style Versus Fashion Orientation on Sustainable Apparel Consumption," Journal of Macromarketing, 39 (2), 188-207.

Gwet, Kilem L. (2008), “Computing Inter-Rater Reliability and Its Variance in the Presence of High Agreement," British Journal of Mathematical and Statistical Psychology, 61 (pt 1), 29-48.

Harrison, K., D. Henley, H. Riley, and J. Shatter (1974), "Improving Food Marketing Systems in Developing Countries: Experiences from Latin America," East Lansing: Marketing in Developing Communities Series, Latin America Studies Center, Michigan State University.

Hunt, Shelby D. and Scott J. Vitell (2006), "The General Theory of Marketing Ethics: A Revision and Three Questions," Journal of Macromarketing, 26(2), 143-53.

Hutter, Katharina and Stefan Hoffmann (2013), "Carrotmob and AntiConsumption: Same Motives but Different Willingness to Make Sacrifices?" Journal of Macromarketing, 33 (3), 217-31.

Johnson, E. J. (2006), "Things that Go Bump in the Mind: How Behavioral Economics Could Invigorate Marketing," Journal of Marketing Research, 43(3), 337-40.

Jones, D. G. Brian and Eric H. Shaw (2006), "Historical Research in the Journal of Macromarketing, 1981-2005," Journal of Macromarketing, 26 (2), 178-92.

Keller, Punam Anand, Donald R. Lehmann, and Katherine J. Milligan (2009), "Effectiveness of Corporate Well-Being Programs: A Meta-Analysis," Journal of Macromarketing, 29 (3), 279-302.

Kilbourne, William E. and Les Carlson (2008), “The Dominant Social Paradigm, Consumption, and Environmental Attitudes: Can Macromarketing Education Help?" Journal of Macromarketing, 28 (2), 106-21.

Kilbourne, William E., Micheal J. Dorsch, Pierre McDonagh, Bertrand Urien, Andrea Prothero, Marko Grünhagen, Micheal Jay Polonsky, David Marshall, Janice Foley, and Alan Bradshaw (2009), "The Institutional Foundations of Materialism in Western Societies: A Conceptualization and Empirical Test," Journal of Macromarketing, 29(3), 259-78.

Klein, Thomas A. (2005), "History of Macromarketing Panel," 30th Annual Macromarketing Conference, St. Petersburg, FL, May 29.

Koch, Matthias and Davide Christian Orazi (2017), "No Rest for the Wicked: The Epidemic Life Cycle of Wicked Consumer Behavior," Journal of Macromarketing, 37 (4), 356-68.

Kozinets, Robert V., Andrea Hemetsberger, and Hope J. Schau (2008), "The Wisdom of Consumer Crowds: Collective Innovation in the Age of Networked Marketing," Journal of Macromarketing, 28(4), 339-54.

Krippendorff, Klaus (1980), Content Analysis: An Introduction to its Methodology, Beverly Hills, CA: Sage.

Krippendorff, Klaus (2013), Content Analysis: An Introduction to its Methodology, (3rd ed.), Los Angeles, CA: Sage.

Kumcu, Erdoğan and M. Ercan Kumcu1 (1987), "Determinants of Food Retailing in Developing Countries: The Case of Turkey," Journal of Macromarketing, 7 (2), 26-40.

Laczniak, Gene R. and Patrick E. Murphy (2006), "Normative Perspectives for Ethical and Socially Responsible Marketing," Journal of Macromarketing, 26 (2), 154-77.

Layton, Roger A. (2009), "On Economic Growth, Marketing Systems, and the Quality of Life," Journal of Macromarketing, 29 (4), 349-62.

Layton, Roger A. (2015), "Formation, Growth, and Adaptive Change in Marketing Systems," Journal of Macromarketing, 35 (3), 302-19.

Layton, Roger A. and Sanford Grossbart (2006), "Macromarketing: Past, Present, and Possible Future," Journal of Macromarketing, 26 (2), 193-213. 
Lombard, M., Jennifer Snyder-Duch, and Cherly C. Bracken (2005), "Practical Resources for Assessing and Reporting Intercoder Reliability in Content Analysis Research Projects." Accessed April 7, 2020. https://www.researchgate.net/publication/242785900_ Practical_Resources_for_Assessing_and_Reporting_Intercoder_ Reliability_in_Content_Analysis_Research_Projects

Lovejoy, Jennette, Brendan R. Watson, Stephen Lacy, and Daniel Riffe (2014), "Assessing the reporting of reliability in published content analyses: 1985-2010," Communication Methods and Measures, 8 (3), 207-11.

Lovejoy, Jennette, Brendan R. Watson, Stephen Lacy, and Daniel Riffe (2016), "Three Decades of Reliability in Communication Content Analyses: Reporting of Reliability Statistics and Coefficient Levels in Three Top Journals," Journalism \& Mass Communication Quarterly, 93 (4), 1135-59.

Mitchell, Robert, Ben Wooliscroft, and James Higham (2010), "Sustainable Market Orientation: A New Approach to Managing Marketing Strategy," Journal of Macromarketing, 30 (2), 160-70.

Mittelstaedt, John D., William E. Kilbourne, and Robert A. Mittelstaedt (2006), "Macromarketing as Agorology: Macromarketing Theory and the Study of the Agora," Journal of Macromarketing, 26 (2), 131-42.

Neuendorf, Kimberly A. (2002). The Content Analysis Guidebook, Thousand Oaks, CA: Sage.

Peterson, Mark (2006), "Focusing the Future of Macromarketing," Journal of Macromarketing, 26 (2), 245-49.

Prothero, Andrea, Pierre McDonagh, and Susan Dobscha (2010), "Is Green the New Black? Reflections on a Green Commodity Discourse," Journal of Macromarketing, 30 (2), 147.

Riffe, Daniel, Stephen Lacy, and Frederick G. Fico (2014), Analyzing Media Messages: Using Quantitative Content Analysis in Research, 3rd ed. New York, NY: Routledge.

Scott, William A. (1955), "Reliability of Content Analysis: The Case of Nominal Scale Coding," Public Opinion Quarterly, 19 (3), 321-25.

Shultz, Clifford J. (2006), "Introduction to the Silver Anniversary Issue," Journal of Macromarketing, 26 (2), 127-30.

Slater, Charles. C. (1965), "The role of Food Marketing in Latin American Economic Development," in Marketing and Economic Development, P. D. Bennett, ed. Chicago: American Marketing Association, 30-37.
Thaler, R. H. and L. J. Ganser (2015). Misbehaving: The Making of Behavioral Economics. New York: WW Norton.

The VOICE Group (2010), "Motherhood, Marketization, and Consumer Vulnerability,” Journal of Macromarketing, 30 (4), 384-97.

The World Bank (2020). https://www.worldbank.org/en/topic/social development/overview

Thøgersen, John (2010), "Country Differences in Sustainable Consumption: The Case of Organic Food," Journal of Macromarketing, 30 (2), 171-85.

Viswanathan, Madhubalan, Anju Seth, Roland Gau, and Avinish Chaturvedi (2009), "Ingraining Product-Relevant Social Good into Business Processes in Subsistence Marketplaces: The Sustainable Market Orientation," Journal of Macromarketing, 29 (4), 406-25.

Wilkie, William L. and Elizabeth S. Moore (2006), "Macromarketing as a Pillar of Marketing Thought," Journal of Macromarketing, 26 (2), 224-32.

Wimmer, Roger D. and Joseph R. Dominick (2003), "Mass Media Research: An Introduction," (7th ed.), Belmont, CA: Wadsworth/ Thomson.

Zhao, Xinshu, Jun S. Liu, and Ke Deng (2012), “Assumptions Behind Intercoder Reliability Indices," in Communication Yearbook 36, C. T. Salmon Ed. New York: Routledge, 419-80.

\section{Author Biographies}

Ahmet Ekici (PhD, University of Nebraska-Lincoln) is an Associate Professor of Marketing at Bilkent University. His main research areas are public policy and marketing; macromarketing and relationship marketing. His refereed articles have been published in a variety of journals including Journal of Macromarketing, Journal of Business Ethics, Industrial Marketing Management, Journal of Business Research, Journal of Public Policy \& Marketing, and Social Indicators Research.

Tugce Ozgen Genc is a graduate student at Bilkent University, Faculty of Business Administration. Ms. Genc received her BSc degree from Middle East Technical University in Food Science and the MBA degree from TOBB University, Ankara-Turkey.

Hafize Celik is a graduate student at Bilkent University, Faculty of Business Administration. Ms. Celik received her BSc degree from Middle East Technical University in Industrial Design. 